\title{
Hydrological drivers of record-setting water level rise on Earth's largest lake system
}

\author{
A.D. Gronewold ${ }^{1,2}$, J. Bruxer ${ }^{3}$, D. Durnford ${ }^{4}$, J.P. Smith $^{5}$, A.H. Clites ${ }^{1}$, F.
}

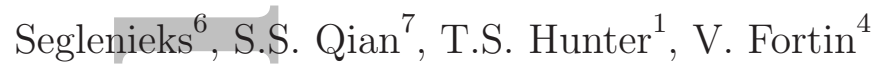

\section{Abstract}

Between January 2013 and December 2014, water levels on Lake Superior and Lake Michigan-Huron, the two largest lakes on Earth by surface area, rose at the highest rate ever recorded for a two-year period beginning in January and ending in December of the following year. This historic event coincided with below-average air temperatures and extensive winter ice cover across the Great Lakes. It also brought an end to a 15-year period of persistently below-average water levels on Lakes Superior and Michigan-Huron that included several months of record-low water levels. To differentiate hydrological drivers behind the recent water level rise, we developed a Bayesian Markov chain Monte Carlo (MCMC) routine for inferring historical estimates of the major components of each lake's water budget. Our results indicate that, in 2013, the water level rise on Lake Superior was driven by increased spring runoff and over-lake precipitation. In 2014, reduced over-lake

Corresponding author: A.D. Gronewold, National Oceanic and Atmospheric Administration, Great Lakes Environmental Research Laboratory, 4840 S. State Rd., Ann Arbor, MI 48108, USA. (drew.gronewold@noaa.gov)

\footnotetext{
${ }^{1}$ National Oceanic and Atmospheric
} 
evaporation played a more significant role in Lake Superior's water level rise. The water level rise on Lake Michigan-Huron in 2013 was also due to above-average spring runoff and persistent over-lake precipitation, while in 2014, it was due to a rare combination of Administration, Great Lakes Environmental

Research Laboratory, Ann Arbor, Michigan,

USA, 48108

${ }^{2}$ University of Michigan, Department of

Civil and Environmental Engineering, Ann

Arbor, Michigan USA, 48109

${ }^{3}$ Environment Canada, Great Lakes - St.

Lawrence Regulation Office, Cornwall,

Ontario, Canada K6H 6S2

${ }^{4}$ Canadian Meteorological Centre, Dorval,

Quebec, Canada H9P 1J3

${ }^{5}$ University of Michigan, Cooperative

Institute for Limnology and Ecosystems

Research, Ann Arbor, Michigan USA, 48109

${ }^{6}$ Environment Canada, Canada Centre for

Inland Waters, Burlington, ON

${ }^{7}$ University of Toledo, Department of

Environmental Sciences, Toledo, Ohio USA, 43606 
below-average evaporation, above-average runoff and precipitation, and very high inflow rates from Lake Superior through the St. Marys River. We expect, in future research, to apply our new framework across the other $\underline{\text { Laurentian }}^{1}$ Great Lakes, and to Earth's other large freshwater basins as well.

\section{Introduction}

Between January 2013 and December 2014, water levels on Lake Superior and Lake Michigan-Huron, the two largest lakes on Earth by surface area [Gronewold et al., 2013a], rose by nearly two-thirds of a meter and one meter, respectively. This rise represents the largest positive water level differential on Lakes Superior and Michigan-Huron over any historical two-year period beginning in January and ending in December of the following year [Gronewold et al., 2015]. The recent rise is all-the-more significant because it directly impacts over 8,000 miles (roughly 13,000 km) of U.S. and Canadian coastline (along the shores of both Lakes Superior and Michigan-Huron), and because it surpasses by at least an order of magnitude the rate of interannual sea level rise along most of North America's marine coasts [Ekman, 1999; Cooper et al., 2008; Gronewold et al., 2013a].

The recent water level rise on Lakes Superior and Michigan-Huron also brings to an end a 15-year period of persistently below-average water levels, including several months that set record monthly lows [Gronewold and Stow, 2014a]. The beginning of that period was marked by a rapid decline in water levels that coincided with one of the strongest El Niño events on record and subsequent above-average surface water temperatures and evaporation rates [Chandra et al., 1998; Assel, 1998; McPhaden, 1999; Assel et al., 2004; Van Cleave et al., 2014; Piccolroaz et al., 2015]. The 2013-2014 rise, in contrast, coincided with an anomalous meridional upper air flow [commonly referred to in the public media 
as the "polar vortex" phenomenon; for details see Blackmon et al., 1977; NOAA National Climatic Data Center, 2014], below-average regional air temperatures, and extensive winter ice cover [Clites et al., 2014a]. However, despite widespread speculation regarding impacts of the cold winter of 2013-2014 on hydrologic response in the Great Lakes region, we know of no definitive study that explicitly identifies anomalies in the components of the regional water balance that would explain the coincident rapid change in Great Lakes water levels. ${ }^{2}$

It is informative to note that, when compared to Lakes Superior and Michigan-Huron, water levels on Lakes Erie and Ontario have remained relatively close to their seasonal and long-term averages over the past 15 years [Clites et al., 2014b]. While understanding differences between long-term water level trends on each of the Great Lakes is an area of ongoing research, water level dynamics on Lakes Erie and Ontario can be explained in part by abundant outflows from upstream lakes (relative to the water supply from within the Lake Erie and Lake Ontario basins) and in part by the regulation of Lake Ontario outflows along the St. Lawrence Seaway near Cornwall, Ontario and Massena, New York [see figure 1 and Lee et al., 1994]. Despite differences in long-term (i.e. interannual and decadal scale) trends, seasonal water levels on all of the Great Lakes have historically followed a strong pattern driven by changes in the regional water budget, with water levels typically rising in the spring, peaking in mid-summer, and declining in the fall [Lenters, 2001; Quinn, 2002; Gronewold and Stow, 2014b]. Importantly, unlike most other large freshwater basins, the annual water budget of the Great Lakes basin is comprised of nearly equal flows of tributary runoff, over-lake precipitation, and over-lake evaporation [Hunter et al., 2015]. 
Multiple historical estimates of the major components of the Great Lakes water budget have been developed [Quinn, 1979; Derecki, 1985; Lofgren et al., 2002; Quinn and Sellinger, 2006; Spence et al., 2011; Deacu et al., 2012; Fry et al., 2014; Hunter et al., 2015], yet due to the massive surface area of the lakes themselves and the historically sparse in situ, year-round, off-shore (i.e. over-lake) meteorological monitoring network [Gronewold and Stow, 2014a], many of these estimates are believed to be biased and (particularly in older records) highly uncertain. Estimates of flows in the channels connecting the Great Lakes are derived using a combination of various numerical methods, the choice of which depends on the unique physical characteristics of each channel. While individual $\underline{\text { methods differ, they are generally derived from point-specific flow measurements (collected }}$ during intermittent seasonal field campaigns), which are related to continuously measured variables (e.g. water levels). Potential sources of uncertainty in these estimates include inaccuracies in the measured flows and discontinuities in flow measurement technology over time. Spatiotemporal variability in channel conditions, including seasonal ice cover and weed growth along the channel floor and sidewalls, represents yet another source of $\underline{\text { uncertainty in flow estimates. Uncertainty in water level measurements due to short-term }}$ $\underline{\text { anomalies in lake surface topography (during strong wind events, for example) can also }}$ impact lake storage. ${ }^{3}$ For further reading on bias and uncertainty in Great Lakes water budget estimates, see Blanken et al. [2011], Holman et al. [2012], and Lofgren et al. [2013].

Therefore, to understand and differentiate hydrological drivers behind the recent water level rise, we developed a Bayesian Markov chain Monte Carlo (MCMC) routine for inferring new historical estimates of the major components of each lake's water budget. Unlike water budget estimation methods used in previous studies, our approach leverages infor- 
mation from multiple models and datasets while acknowledging and resolving the explicit bias and uncertainty of each source. This approach has two important advantages; first, it allows us to develop estimates that resolve the regional water budget across monthly and interannual time scales. We know of no other study that does so over a multi-year period for the North American Great Lakes. Second, our approach represents an important stepping stone towards addressing a long-standing need in the Great Lakes for clear and defensible differentiation between hydrological [Watras et al., 2014], climatological [Stakhiv, 2011; Brown et al., 2011], geological [Mainville and Craymer, 2005], and anthropogenic [Quinn and Edstrom, 2000] drivers behind seasonal and long-term changes in Great Lakes water levels including those observed in 2013 and 2014. For further discussion on the importance of differentiating drivers of the Great Lakes water cycle, particularly with respect to water resources management and socioeconomic impacts, see Annin [2006], Millerd [2010], and Gronewold and Stow [2014a].

\section{Methods}

Our study focuses on developing new estimates of the major components of the Lake Superior and Lake Michigan-Huron monthly water budget from January 2005 through December 2014, followed by a detailed analysis of those components from January 2013 through December 2014 to better understand drivers of the recent water level rise. In the following sections, we describe the water balance model used to develop those estimates, the sources of data for each water budget component, and our model calibration and validation procedure. For reference, a summary of all model variables and parameters $\underline{\text { described in the following sections is included in table }}{ }^{4} 1$. 


\subsection{The model}

We develop new estimates of the monthly water budget for Lakes Superior and MichiganHuron through a Bayesian analysis (described in section 3.3) of the following conventional water balance models [Arnold et al., 1998; Kebede et al., 2006; Swenson and Wahr, 2009]:

$\delta_{j}^{s}=\sum_{1}^{J}\left(\gamma_{j}^{s}-\lambda_{j}^{s}+\rho_{j}^{s}+\alpha_{j}^{s}-\beta_{j}^{s}+\omega_{j}^{s}\right)$

$\delta_{j}^{m}=\sum_{1}^{J}\left(\gamma_{j}^{m}-\lambda_{j}^{m}+\rho_{j}^{m}+\alpha_{j}^{m}+0.7 \times \beta_{j}^{s}-\beta_{j}^{m}+\omega_{j}^{m}\right)$

where $\delta_{j}$ is the cumulative change in lake storage from January 1, 2005 through the end of month $j(j \in[1, J=120])$ for either Lake Superior (indicated by superscript $s$ ) or Lake Michigan-Huron (indicated by superscript $m$ ). Variables $\gamma_{j}, \lambda_{j}$, and $\rho_{j}$ represent, respectively, monthly over-lake precipitation, over-lake evaporation, and tributary runoff. These variables, and all other variables in equations 1 and 2, are expressed as relative water heights, in $\mathrm{mm}$, over the surface of each respective lake. The variable $\alpha_{j}^{s}$ represents the total monthly flow of water into Lake Superior through interbasin diversions (see figure 1), and $\beta_{j}^{s}$ represents outflows from Lake Superior through the St. Marys River. Similarly, $\alpha_{j}^{m}$ represents the total monthly flow of water into the Lake Michigan-Huron system through interbasin diversions (diversions of water out of the basin are represented as negative values), and $\beta_{j}^{m}$ represents outflows from the Lake Michigan-Huron system through the St. Clair River. Finally, we represent inflows to the Lake Michigan-Huron system through the St. Marys River as a product of outflows from Lake Superior through the St. Marys river $\left(\beta_{j}^{s}\right.$, which is expressed as a water depth over the surface of Lake 
Superior) and a scaling factor (0.7) accounting for the ratio between the surface area of Lake Superior and the surface area of Lake Michigan-Huron.

Historical research on the Great Lakes indicates that major diversions and interconnecting channel flows $(\alpha$ and $\beta$ ), over-lake precipitation $(\gamma)$, over-lake evaporation $(\lambda)$, and runoff $(\rho)$ collectively account for nearly all of the flows into and out of each lake basin. Minor contributions to changes in lake storage, including groundwater fluxes [Grannemann et al., 2000], thermal expansion [Quinn and Guerra, 1986], isostatic rebound [Mainville and Craymer, 2005], and consumptive use [Annin, 2006], are collectively represented in equations 1 and 2 by $\omega$.

\subsection{Data}

\subsubsection{Lake storage, connecting channel flows, and diversions \\ r c o}

The most readily-available and historically-consistent basis for inferring cumulative monthly changes in storage for each of the Great Lakes $\left(\delta_{j}\right)$ is the set of beginningof-month (BOM) water level records maintained by the United States Army Corps of Engineers Detroit District (USACE) and Environment Canada (EC) through the binational Coordinating Committee on Great Lakes Basic Hydraulic and Hydrologic Data (hereafter referred to as the "Coordinating Committee"). This record is based on an international network of shoreline gauging stations operated by the National Oceanic and Atmospheric Administration (NOAA) National Ocean Service (NOS) Center for Operational Oceanographic Products and Services (CO-OPS), and the Department of Fisheries and Oceans (DFO) Canadian Hydrographic Service (CHS). We represent observed cumulative changes in lake storage $y_{j}^{\delta}$ as the measured difference between the water level at the end of month $j$ and the water level at the beginning of January 2005. Alternative 
sources of information for inferring Great Lakes water levels and lake storage are available, including satellite data, geological formations, and shoreline features [Baedke and Thompson, 2000; Holcombe et al., 2003; Quinn and Sellinger, 2006; Wiles et al., 2009; Crétaux et al., 2011; Johnston et al., 2012]. Incorporating these additional sources into Great Lakes water budget estimates is an important area for future research, but one we consider outside the scope of our current study.

Long-term historical estimates of monthly flows through the channels that connect the Great Lakes (i.e. interconnecting channels), including the St. Marys, St. Clair, Detroit, and Niagara Rivers (figure 1), are maintained by the Coordinating Committee. These flow estimates, hereafter referred to as internationally-coordinated flows (or ICFs) and represented by $y^{\beta_{1}}$, have historically been based on a range of calculation methods that relate to flow measurement type, location, and length of record. For example, the ICFs for Lake Superior outflow are calculated as the total flow measured through regulatory structures at the head of the St. Marys River (including three hydropower facilities, navigation locks, the St. Marys Rapids Compensating Works Structure, and local domestic water withdrawals), while ICFs for the St. Clair and Detroit Rivers are based on conventional stage-fall-discharge relationships using water level measurements from USACE, NOAA-NOS-COOPs, and DFO-CHS gauging stations [Quinn, 1985]. Within the past 10 years, international gauging stations (IGS) with acoustic doppler current profilers (ADCPs) have been established through a partnership between the United States Geological Survey (USGS) and Water Survey of Canada (WSC) to support index-velocity estimates of connecting channel flows. We use these as a second source of interconnecting channel flow estimates $\left(y^{\beta_{2}}\right)$. Additional channel flow estimates have been developed [Read et al., 
2010]; however, ${ }^{5}$ aside from the ICF and IGS estimates, we know of none that are readilyavailable or that have been systematically extended across all of the channels of the Great Lakes for a relatively long historical period.

The Coordinating Committee also maintains long-term historical records of diversions of water into, and out of, the Great Lakes basin [Quinn and Edstrom, 2000; Annin, 2006]. The two most significant diversions include the re-routing of water from the Hudson Bay basin into the Great Lakes basin via Long Lake and the Ogoki River, and the re-routing of water out of the Great Lakes basin into the Mississippi River basin through the Chicago Sanitary and Ship Canal (figure 1). Monthly records of the Long Lake (also referred to as Long Lac) and Ogoki diversions are obtained by the Coordinating Committee from Ontario Power Generation, and estimates of the diversions at Chicago are obtained by the Coordinating Committee from the USACE. While we represent these historical estimates in our model as $y^{\alpha}$, we also acknowledge they are orders of magnitude less than the other major components of the Great Lakes water budget. Therefore, while the results of our study reflect the influence of interbasin diversions on lake storage, we do not present estimates of their posterior distributions. For further reading on the Long Lake and Ogoki diversions, including different approaches to accounting for them in runoff estimates into Lakes Superior and Michigan-Huron, see Hunter et al. [2015].

\subsubsection{Over-lake precipitation, over-lake evaporation, and runoff}

Multiple estimates of over-lake precipitation $(\gamma)$, over-lake evaporation $(\lambda)$, and runoff $(\rho)$ have been developed for the Great Lakes. Some were developed specifically for regional water budget accounting, some for regional water level forecasting [Lofgren et al., 2002; Notaro et al., 2006; Hunter et al., 2015], and others as byproducts of large-scale regional 
climate model simulations and reanalysis products targeting a broad (e.g. CONUS) spatial domain [Mesinger et al., 2006]. Here, we consider estimates of $\gamma, \lambda$, and $\rho$ from two sources.

The first is NOAA-GLERL's historical monthly Great Lakes hydrometeorological database [or GLM-HMD, as described in Hunter et al., 2015]. This database represents the only record of Great Lakes hydrological data that extends spatially over the entire domain of the Great Lakes basin (i.e. the land and lake surfaces of the basin across both United States and Canada), and temporally over several decades. For some variables, this database extends as far back as the beginning of the 20th century; however, ${ }^{6}$ many of these historical estimates are believed to be biased [Watkins et al., 2007; Holman et al., 2012] and relatively uncertain, particularly from periods when basin-wide monitoring networks were sparse [Fry et al., 2013, 2014]. We represent over-lake precipitation and over-lake evaporation estimates from the GLM-HMD as $y^{\gamma_{1}}, y^{\lambda_{1}}$, and $y^{\rho_{1}}$, respectively.

Our second source of historical estimates for over-lake precipitation and over-lake evaporation is the Canadian Meteorological Centre's GEM modeling system [Pietroniro et al., 2007; Deacu et al., 2012]. For this study, we employed over-lake precipitation estimates from GEM in its RDPS (Regional Deterministic Prediction System) formulation, and over-lake evaporation estimates from GEM-Surf using parameterizations documented in Deacu et al. [2012]. For additional reading on the GEM-Surf system, see Carrera et al. [2010] and Bernier and Bélair [2012]. While the GEM system of models simulates variables for a much shorter period of record (roughly 2005 through 2014) relative to the NOAA-GLERL GLM-HMD, it is believed to provide a more realistic representation of atmospheric and meteorological conditions over the surfaces of the lakes and, potentially, more accurate estimates of over-lake evaporation and over-lake precipitation [Mahfouf 
et al., 2007; Deacu et al., 2012]. We represent over-lake precipitation and over-lake evaporation estimates from GEM and GEM-Surf, respectively, as $y^{\gamma_{2}}$ and $y^{\lambda_{2}}$. Estimates of runoff from the GEM modeling system were not available for the period of focus in this study; however, ${ }^{7}$ we intend to include GEM runoff estimates in future research.

\subsection{Model calibration (parameter inference)}

We calibrate the water balance models in equations 1 and 2 using a Bayesian MCMC routine [Bernardo and Smith, 1994; Press, 2003; Bolstad, 2004; Gelman et al., 2004], an approach that allows us to combine multiple sources of information about each water budget component across time, either as a priori estimates (represented by prior probability distribution functions) or as updates to those estimates (in the form of likelihood functions). We begin with the assumption that the observed net water level differential at the end of month $j$ (i.e. $y_{j}^{\delta^{s}}$ and $y_{j}^{\delta^{m}}$ ), a proxy for cumulative change in storage, is a normally-distributed random variable (we hereafter remove superscripts $s$ and $m$ for clarity) $y_{j}^{\delta} \sim \operatorname{No}\left(\delta_{j}, \tau^{y^{\delta}}\right)$ with mean $\delta_{j}$ and precision $\tau^{y^{\delta}}$. We parameterize normal and lognormal probability distributions using precision (where precision is defined as $1 / \sigma^{2}$, and $\sigma$ is standard deviation), ${ }^{8}$ rather than standard deviation or variance, to be consistent with the coding protocols of the BUGS (Bayesian inferencing Using Gibbs Sampling) and JAGS (Just Another Gibbs Sampler) suite of software packages described later in this

section and in the supporting information. Here, $\tau^{y^{\delta}}$ accounts not only for uncertainty and minor errors in water level measurements, but also for water level measurement variability introduced through thermal expansion, groundwater fluxes, and other sources of variability described in section 3.1. 
We model $\alpha_{j}, \beta_{j}, \gamma_{j}, \lambda_{j}$, and $\rho_{j}$ as unknown quantities with relatively informative prior probability distributions [Press, 2003] based on data from the NOAA-GLERL GLM-HMD between 1950 and 2004. Following previous studies [Thom, 1958; Husak et al., 2007; Gronewold et al., 2013b], we assign a gamma prior probability distribution to over-lake precipitation $\pi\left(\gamma_{j}\right) \sim \mathrm{Ga}\left(\psi_{m[j]}^{1}, \psi_{m[j]}^{2}\right)$ for each of the twelve months $(m)$ of the year with shape $\psi^{1}$, rate $\psi^{2}$, mean $\psi^{1} / \psi^{2}$, and variance $\psi^{1} /\left(\psi^{2}\right)^{2}$. We calculate $\psi_{m}^{1}$ and $\psi_{m}^{2}$ using the following maximum likelihood estimates from Husak et al. [2007]:

$\psi_{m}^{1}=\frac{1}{4 \phi_{m}}\left(1+\sqrt{1+\frac{4 \phi_{m}}{3}}\right)$

$\phi_{m}=\ln \left(\bar{y}_{m}^{\gamma}\right)-\frac{\sum_{i=1}^{N} \ln \left(y_{i}^{\gamma}\right)}{N}$

$\psi_{m}^{2}=\psi_{m}^{1} / \bar{y}_{m}^{\gamma}$

where $\bar{y}_{m}^{x}$ is the average precipitation for month $m$ from 1950 through 2004 from the GLM-HMD, and $N$ is the number of years over that period.

We then assign normal $\operatorname{No}\left(\mu_{m[j]}^{*}, \tau_{m[j]}^{*}\right)$ prior probability distributions to $\alpha, \beta$, and $\lambda$ (collectively represented by ${ }^{*}$ ), with mean $\mu_{m}^{*}$ and precision $\tau_{m}^{*}$ calculated, respectively, as the mean and precision of each variable in month $m$ from 1950 through 2014 using data from the NOAA-GLERL GLM-HMD. Finally, we assign a lognormal LN $\left(\mu_{m[j]}^{\rho}, \tau_{m[j]}^{\rho}\right)$ prior probability distribution to monthly runoff with $\log$-mean $\mu_{m}^{\rho}$ and $\log$-precision $\tau_{m}^{\rho}$, also based on data over the 1950 to 2014 period from the NOAA-GLERL GLM-HMD. $\underline{\text { A graphical representation of our approach to developing prior probability distributions }}$ $\underline{\text { for every other month starting in January is included in figure }}{ }^{9}$. For a graphical rep- 
resentation of prior probability distributions for all months on both Lakes Superior and Michigan-Huron, see figures S1 and S2 in the supporting information.

We update estimates of each monthly water budget component using the observations and measurements described in section 3.2 (i.e. $y_{j}^{*_{1}}$ and $y_{j}^{*_{2}}$ ) for the period of record beginning in January 2005 and ending December 2014 using the following normal likelihood functions:

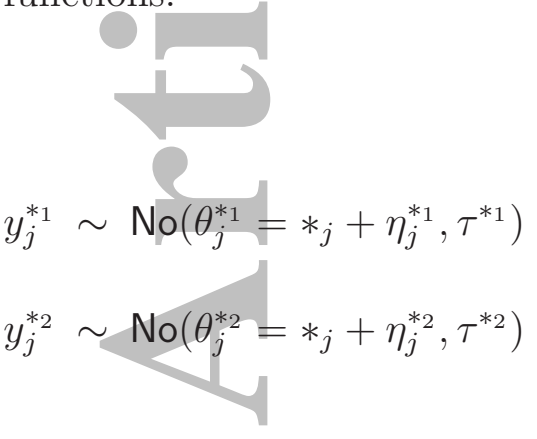

where $\theta^{*_{1}}$ and $\theta^{*_{2}}$ are the inferred mean for each water budget component $(*)$ based on data source 1 and 2 , respectively, and $*_{j}$ represents the inferred mean for the water budget component integrated across all data sources. The parameters $\eta_{j}^{*_{1}}$ and $\eta_{j}^{*_{2}}$ represent seasonal (i.e. monthly) bias in each data source for each water budget component, and are assigned non-informative No(0, 0.01) prior probability distributions. Precision parameters $\tau^{*_{1}}$ and $\tau^{*_{2}}$ are also assigned non-informative $\mathrm{Ga}(0.1,0.1)$ prior probability distributions [Browne and Draper, 2006; Gelman, 2006]. We selected historical data from 2005 through 2014 as a basis for our likelihood functions because it is the most recent period for which estimates from both GLM-HMD and the GEM modeling system are available, and because it includes the two years (2013 and 2014) of the recent water level rise.

$\underline{\text { Because our model is intended to improve inference of historical basin-scale }}$ $\underline{\text { spatially-averaged water budget components by utilizing any and all available }}$ $\underline{\text { measurements, estimates, and model simulations, it does not necessarily warrant }}$ $\underline{\text { traditional model validation procedures often applied to forecasting models }}{ }^{12}$ [for fur- 
ther discussion, see Reckhow and Chapra, 1983]. Nonetheless, in order to further explore $\underline{\text { and better understand the range of potential applications of our new procedure, including }}$ water budget inference during historical periods for which there are no corresponding measurements, we conduct a simple validation in which we rerun our new model while systematically leaving out all estimates for one of each of the three major water budget components (i.e. $\gamma, \lambda, \rho$ ) from 2010 through 2014. We then assess the impact of removing observations on not only the inferred water budget components during this period, but also on the posterior predictive distribution of expected estimates from both GLM-HMD and GEM. ${ }^{13}$

We simulate samples from posterior probability distributions of each monthly water budget component (as well as the posterior predictive distributions of GLM-HMD and GEM estimates from 2010 through 2014 in our validation procedure) ${ }^{14}$ using the MCMC procedures encoded in the BUGS and JAGS software packages [Lunn et al., 2000; Plummer, 2003; Lunn et al., 2009]. While we ran model simulations using both BUGS (via the OpenBUGS interface) and JAGS, we found (results not shown) no noticeable difference between the two; methodology and results hereafter refer to models implemented within the JAGS system.

We ran five MCMC chains until each converged, indicated by a potential scale reduction factor $\hat{R}$ close to 1.0 [Gelman et al., 2004]. A graphical summary of our approach to $\underline{\text { developing posterior probability distributions for Lake Superior monthly water budget }}$ $\underline{\text { components for every other month (starting in January) of } 2014 \text { is included in figure }}{ }^{15}$

3. Our JAGS code is included in the supporting information, along with plots (figures S3 and S4) documenting the evolution of posterior probability distribution for all months 
of 2014 on both Lakes Superior and Michigan-Huron. For further reading on Bayesian $\underline{\text { methods (including applications of MCMC to water resource and environmental science }}$ $\underline{\text { problems) }}^{16}$, see Qian and Richardson [1997], Qian et al. [2003], Obenour et al. [2014], and Cha et al. [2016].

\section{Results and discussion}

A comparison between a time series of our new monthly water budget estimates and deterministic estimates from previous research for both Lakes Superior (figure 4) and Michigan-Huron (figure 5) indicates how, through an expression of uncertainty, our new estimates collectively explain not only the variability across the historical deterministic estimates for each water budget component (top four panels in figures 4 and 5) but also the "observed" (i.e. based on BOM water levels) cumulative changes in lake storage (bottom panel of figures 4 and 5). Thus our new estimates "close" the regional water budget and provide a robust basis for differentiating hydrologic drivers of the recent water level rise. It is informative to note that this study not only represents the first of its kind to close the water budget of the Great Lakes for any historical period, but it does so through an appropriate accounting of bias and uncertainty (for details on our estimates of bias, see figures S5 and S6 in the supporting information).

Our model validation results (figure 6) underscore the value of water budget in situ $\underline{\text { measurements, empirical estimates, and numerical modeling simulations when attempting }}$ $\underline{\text { to close the regional water balance, particularly during periods of extreme changes in lake }}$ storage. For example, when historical estimates of over-lake precipitation are removed $\underline{\text { from our new modeling procedure from } 2010 \text { through 2014, we obtain (top row figure } 6 \text { ) }}$ $\underline{\text { over-lake precipitation estimates not much different from those obtained with historical }}$ 
estimates in 2010, 2011, 2012 and 2013, but very different estimates in 2014. This result indicates that without either the GLM-HMD or GEM estimates of over-lake precipitation, our new modeling procedure would infer very high over-lake precipitation estimates in 2014 $\underline{\text { in order to explain the surge in water levels. Similarly, if we exclude historical evaporation }}$ $\underline{\text { estimates from our new modeling procedure, our inferred over-lake evaporation estimates }}$ $\underline{\text { (middle row figure } 6 \text { ) would have been much lower in order to coincide with the increase }}$ $\underline{\text { in water levels. This result has important implications for how we might use our model to }}$ infer historical estimates of the water budget in periods when monitoring infrastructure was even more sparse than it is today. We may find, in future research, that extending our $\underline{\text { model back in the historical record may require either more informative prior estimates of }}$ $\underline{\text { monthly water budget components, or a more complex approach to representing spatial }}$ $\underline{\text { correlation in over-lake and over-lake precipitation. Our results also indicate that our new }}$ $\underline{\text { modeling tool has the potential to guide monitoring infrastructure planning decisions. }}{ }^{19}$

$\underline{\text { A comparison between different approaches to calculating cumulative changes in lake }}$ storage (figure 7) further underscores the benefits of our new method. For example, the estimated change in lake storage from 2005 through 2014 using a combination of the GEM-MESH system for over-lake precipitation $(\gamma)$ and over-lake evaporation $(\lambda)$, the GLM-HMD for runoff $(\rho)$, and internationally-coordinated connecting channel flow estimates would have been greater than the observed change in storage by close to 1.2 $\underline{\text { meters on Lake Superior, and } 1.6 \text { meters on Lake Michigan-Huron, respectively (blue }}$ lines figure 7). Similarly, the estimated change in lake storage over this period using only estimates from the GLM-HMD and the internationally-coordinated channel flow estimates would have been roughly 1.1 meters less than the observed change in storage 
on Lake Superior, and 0.8 meters greater than the observed change in storage on Lake Michigan-Huron. From a long-term water balance perspective, our new procedure (for which cumulative lake storage estimates are compared to observations in the bottom $\underline{\text { panels of figures } 4 \text { and 5) appears to represent a more desirable and robust alternative. }}{ }^{22}$

In addition to confirming water budget closure and helping visualize the relationship between parameter uncertainty and measurement variability, the time series of our new water budget component estimates (figures 4 and 5) provides a clear indication of the hydrological drivers behind the recent water level rise. The water level rise on Lake Superior, for example, based on visual analysis of figure 4, was a consequence of persistently high ${ }^{25}$ over-lake precipitation and high spring runoff, particularly in 2013, and occurred despite relatively high outflows to Lake Michigan-Huron through the St. Marys River. Similarly, the water level rise on Lake Michigan-Huron (figure 5) was a consequence of persistently high over-lake precipitation, particularly from late spring through the fall of 2014, and (as on Lake Superior) relatively high runoff in spring 2013.

A month-by-month analysis of these components from January 2013 through December 2014 (figures 8 and 9) provides additional insight into the hydrologic drivers of the recent water level rise, and how those drivers differed across seasons, and across each lake, in both 2013 and 2014. For example, the magnitude of our new monthly water budget components across each season and lake system between 2013 and 2014 (top portions figures 8 and 9) are consistent with previous findings [Lenters, 2001; Quinn, 2002; Spence et al., 2013; Van Cleave et al., 2014], with high over-lake evaporation in late fall and early spring, high runoff in late spring, and persistent over-lake precipitation throughout the year. However, the anomalies in these components relative to our new monthly averages from 2005 through 
2014 indicate that, on Lake Superior (bottom section figure 8), the three months with the highest anomalies in month-to-month water level differential (i.e. May 2013, July 2013, and May 2014) were characterized by a combination of above-average runoff and over-lake precipitation, and little appreciable departure from average evaporation. In contrast, in the months with the four next highest anomalies in month-to-month water level differential on Lake Superior (i.e. August 2013, February 2014, September 2014, and December 2014), below-average over-lake evaporation was the most important factor.

It is informative to note that the persistent below-average over-lake evaporation on Lake Superior in 2014 was likely a consequence of cold winter 2013-2014 conditions that, among other regional impacts, reduced lake heat content and surface water temperatures [Spence et al., 2013], and led to unusually expansive ice cover [Clites et al., 2014a]. It is also informative to note that the persistent above-average outflows from Lake Superior from August 2013 through December 2014 are the result of complex relationships between water levels on Lakes Superior and Michigan-Huron, and the plans that guide regulation of Lake Superior outflows. Generally, Lake Superior outflows to Lake Michigan-Huron, as with unregulated Lake Michigan-Huron outflows to Lake Erie, are driven by the surface water differential between the upstream and downstream lakes and the characteristics of the channel that connects them. In early 2013, high precipitation and runoff propagated into a rapid rise in water levels on Lake Superior in part because Lake Superior and Lake Michigan-Huron water levels were both so low. If water levels across Lake Superior and Lake Michigan-Huron in early 2013 had been higher, outflows from Lake Superior would have been higher in early 2013 as well. 
On Lake Michigan-Huron, the three most anomalous monthly water level differentials in 2013 (i.e. in April, May, and November) were characterized by above-average runoff (in each of these three months, runoff was the most important driver) and above-average over-lake precipitation (bottom figure 9). The next three highest monthly water level differential anomalies in 2013 were characterized by either high runoff (February), belowaverage evaporation (August), or a combination of above-average over-lake precipitation, runoff, and inflows from Lake Superior (October). In 2014, however, the continuous aboveaverage water level differentials on Lake Michigan-Huron from April through December were driven by a rare combination of above-average contributions from precipitation and $\underline{\text { runoff, and below-average losses from over-lake evaporation }}{ }^{30}$. This finding underscores the broad collective impact of the cold winter of 2013-2014 (through reduced evaporation on both Lakes Superior and Michigan-Huron), the hydrologic connectivity between the lakes (flows through the St. Clair River from Lake Michigan-Huron started to increase in mid-2014, just after flows into Lake Michigan-Huron through the St. Marys River had started to $\underline{\text { increase }}^{31}$ ), and persistent above-average precipitation rates (particularly from March through November) across the basin.

When viewed as cumulative two-year anomalies from 2013 through 2014 (figure 10), our water budget estimates indicate that over-lake precipitation was the most important (i.e. most anomalous) driver on Lake Superior, constituting $380 \mathrm{~mm}$ (70\%) of the $540 \mathrm{~mm}$ two-year water level rise anomaly through a combination of three very high months of precipitation in the spring of 2013, and persistent above-average precipitation across nearly all of 2014. In contrast, tributary runoff was the most important driver on Lake MichiganHuron, accounting for $320 \mathrm{~mm}$ (40\%) of the $830 \mathrm{~mm}$ two-year water rise anomaly. This 
finding is not altogether surprising because of the close relationship between regional precipitation and runoff, and because the land-to-lake area ratio of the Lake Michigan-Huron basin is higher than that of the Lake Superior basin.

Cumulative anomalies in over-lake evaporation account for about $140 \mathrm{~mm}$ of the water level rise anomaly on Lake Superior and roughly $110 \mathrm{~mm}$ of the water level rise anomaly on Lake Michigan-Huron. The cumulative anomaly of combined over-lake precipitation and over-lake evaporation, however, was very high (520 mm on Lake Superior, and $270 \mathrm{~mm}$ on Lake Michigan-Huron; figure 10), a finding that underscores the impact of lake-atmosphere interactions on the water budget of Earth's two largest freshwater surfaces. Our findings also underscore the importance of ongoing research, including deployment of off-shore, in situ instrumentation, processing of satellite observations, and development of highspatiotemporal resolution models aimed at improving understanding of those interactions [Blanken et al., 2011; Spence et al., 2011; Gronewold and Fortin, 2012; Spence et al., 2013].

Finally, the two-year cumulative anomalies of each water budget component reflect how over-lake precipitation on Lake Superior, and runoff into Lakes Superior and MichiganHuron, were the most important factors in the first year of the water level rise, while over-lake evaporation on both lake systems, along with over-lake precipitation on Lake Michigan-Huron, were close to average in 2013. The second year of the rise was characterized by persistent above-average precipitation along with a reduction in over-lake evaporation on both lake systems, and a consistent rise in flows through the St. Marys River. 


\section{Conclusions}

Our development and analysis of new estimates for the components of the monthly water budgets of Lakes Superior and Michigan-Huron from January 2005 through December 2014 indicate that the amplification of the seasonal water level cycle and the net gain in water levels from January 2013 through December 2014 was driven by a combination of hydrologic factors that varied from year-to-year, and across the seasons within each year. In 2013, water level gains on Lake Superior were due primarily to increases in runoff and over-lake precipitation in the spring, while water level gains on Lake Michigan-Huron were also due primarily to increases in runoff and over-lake precipitation; however, ${ }^{32}$ those increases occurred in both the spring and late fall. In 2014, below-average evaporation, above-average runoff, over-lake precipitation, and flow rates through the St. Marys River were all factors in the above-average water level rise across each lake system.

While the findings from our study represent an important stepping stone towards an improved understanding of recent hydrological phenomena on Earth's largest system of lakes, they also were developed through a statistical modeling framework that can be used to develop more comprehensive (i.e. across a longer period and across all lakes) historical records of the Great Lakes water budget while accommodating additional observations and data sets as they become available. Important features of this framework include representation of objective and subjective a priori information [Press, 2003] on water budget components (see figures S1 and S2 for evolution of the prior probability distributions for this study) and the ability to accommodate multiple estimates of each component with quantification of each estimate's bias (figures S5 and S6). We expect, in future research, 
to apply this framework not only to the other Great Lakes, but to large lakes in other parts of the world as well.

We also expect that the results of our analysis will lead to research exploring how the water budget and water levels of the Great Lakes, and of Earth's other large freshwater systems, respond to regional short-term climate perturbations and long-term climate trends. This insight could provide important guidance on water resource management policy. In the Great Lakes, for example, the general public often demands new or supplemental anthropogenic controls (i.e. flow control structures) when water levels reach extreme highs or lows [Gronewold and Stow, 2014a]. When water levels are low, these demands are backed 27

by claims that water loss is driven by human intervention (e.g. historical dredging operations, agricultural practices, and consumptive use) and should therefore be compensated through human intervention. Interestingly, when water levels on the Great Lakes are high (as they were in the mid-1980s), demands for human intervention to increase outflows through water diversions and increased dredging arise, even though persistent increases in Great Lakes water levels are not commonly attributed to direct human intervention.

\section{Acknowledgements}

This work was supported by NOAA, USACE, and EC. The data used are listed in the references and supplementary information, and are freely available through NOAA, USACE, and EC. The authors thank Craig Stow, David Holtschlag, and Brent Lofgren for technical comments. Cathy Darnell and Nicole Rice provided graphical and editorial support. This is NOAA-GLERL contribution No. XXXX. 


\section{Notes}

1. R1C3: North American

2. text added by AE1

3. text added by R3C1

4. text added by R3C2

5. AE2: however

6. AE2: ,however

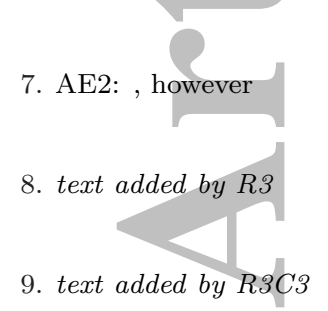

10.text added by R3C3

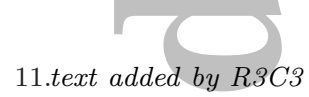

12 text added by $R 3 C 4$

12.text added by $R 3 C 4$

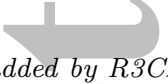

13.text added by $\mathrm{R} 3 \mathrm{C} 4$

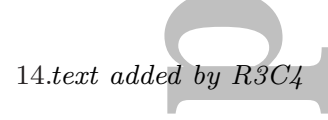

15.text added by R3C3

16.text added by R3

17.text added by R3C3

18.text added by R3C3

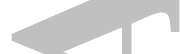

19.text added by R3C4

20.text added by $R 3 C 4$

21.text added by R3C4 
22.text added by R2

23.text added by $n / n$

24.text added by $n / n$

25.R2C2: persistent

26.text added by $R_{4} C 7$

27.text added by $R_{4} C 7$

28.text added by $R_{4} C 7$

29.text added by $R_{4} C r$

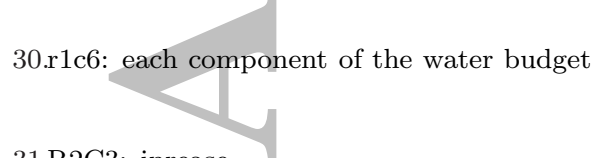

31.R2C3: inrease

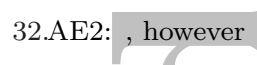

\section{References}

Annin, P. (2006), Great Lakes Water Wars, Island Press, Washington, DC.

Arnold, J. G., R. Srinivasan, R. S. Muttiah, and J. R. Williams (1998), Large area hydrologic modeling and assessment part I: model development, JAWRA Journal of the American Water Resources Association, 34(1), 73-89.

Assel, R. A. (1998), The 1997 ENSO event and implications for North American Laurentian Great Lakes winter severity and ice cover, Geophysical Research Letters, 25(7), $1031-1033$.

Assel, R. A., F. H. Quinn, and C. E. Sellinger (2004), Hydroclimatic factors of the recent record drop in Laurentian Great Lakes water levels, Bulletin of the American Meteorological Society, 85(8), 1143-1151. 
Baedke, S. J., and T. A. Thompson (2000), A 4,700-year record of lake level and isostasy for Lake Michigan, Journal of Great Lakes Research, 26(4), 416-426.

Bernardo, J. M., and A. F. M. Smith (1994), Bayesian Theory, John Wiley \& Sons, Ltd., West Sussex, UK.

Bernier, N. B., and S. Bélair (2012), High horizontal and vertical resolution limitedarea model: Near-surface and wind energy forecast applications, Journal of Applied Meteorology and Climatology, 51(6), 1061-1078.

Blackmon, M.L., J. M. Wallace, N. C. Lau, and S. L. Mullen (1977), An observational study of the Northern Hemisphere wintertime circulation, Journal of Atmospheric Sciences, $34(7), 1040-1053$.

Blanken, P. D., C. Spence, N. Hedstrom, and J. D. Lenters (2011), Evaporation from Lake Superior: 1. Physical controls and processes, Journal of Great Lakes Research, 37(4), $707-716$.

Bolstad, W. M. (2004), Introduction to Bayesian Statistics, Wiley-Interscience, Hoboken, N.J.

Brown, C., W. Werick, W. Leger, and D. Fay (2011), A decision-analytic approach to managing climate risks: application to the Upper Great Lakes, JAWRA Journal of the American Water Resources Association, 47(3), 524-534.

Browne, W. J., and D. Draper (2006), A comparison of Bayesian and likelihood-based methods for fitting multilevel models, Bayesian Analysis, 1(3), 473-514.

Carrera, M. L., S. Bélair, V. Fortin, B. Bilodeau, D. Charpentier, and I. Doré (2010), Evaluation of snowpack simulations over the Canadian Rockies with an experimental hydrometeorological modeling system, Journal of Hydrometeorology, 11(5), 1123-1140. 
Cha, Y., S. S. Park, H. W. Lee, and C. A. Stow (2016), A Bayesian hierarchical approach to model seasonal algal variabilty along an upstream to downstream river gradient, Water Resources Research, 52.

Chandra, S., J. R. Ziemke, W. Min, and W. G. Read (1998), Effects of 1997-1998 El Niño on Tropospheric Ozone and Water Vapor, Geophysical Research Letters, 25(20), $3867-3870$.

Clites, A. H., J. Wang, K. B. Campbell, A. D. Gronewold, R. A. Assel, X. Bai, and G. A. Leshkevich (2014a), Cold water and high ice cover on Great Lakes in spring 2014, Eos, Transactions American Geophysical Union, 95(34), 305-306.

Clites, A. H., J. P. Smith, T. S. Hunter, and A. D. Gronewold (2014b), Visualizing relationships between hydrology, climate, and water level fluctuations on Earth's largest system of lakes, Journal of Great Lakes Research, 40(3), 807-811.

Cooper, M. J. P., M. D. Beevers, and M. Oppenheimer (2008), The potential impacts of sea level rise on the coastal region of New Jersey, USA, Climatic Change, 90(4), $475-492$.

Crétaux, J.-F., W. Jelinski, S. Calmant, A. Kouraev, V. S. Vuglinski, M. Bergé-Nguyen, M. C. Gennero, F. Nino, R. A. Del Rio, and A. Cazenave (2011), SOLS: A lake database to monitor in the near real-time water level and storage variations from remote sensing data, Advances in Space Research, 47(9), 1497-1507.

Deacu, D., V. Fortin, E. Klyszejko, C. Spence, and P. D. Blanken (2012), Predicting the net basin supply to the Great Lakes with a hydrometeorological model, Journal of Hydrometeorology, 13(6), 1739-1759. 
Derecki, J. A. (1985), Effect of channel changes in the St. Clair River during the present century, Journal of Great Lakes Research, 11(3), 201-207.

Ekman, M. (1999), Climate changes detected through the world's longest sea level series, Global and Planetary Change, 21 (4), 215-224.

Fry, L., T. S. Hunter, M. S. Phanikumar, V. Fortin, and A. D. Gronewold (2013), Identifying streamgage networks for maximizing the effectiveness of regional water balance modeling, Water Resources Research, 49(5), 2689-2700.

Fry, L., A. D. Gronewold, V. Fortin, D. Holtschlag, S. Buan, A. H. Clites, T. S. Hunter, F. Seglenieks, E. Klyszejko, C. Luukkonen, L. Diamond, D. Durnford, M. Dimitrijevic, C. Subich, K. Kea, and P. Restrepo (2014), The Great Lakes Runoff Intercomparison Project Phase 1: Lake Michigan (GRIP-M), Journal of Hydrology, 519(Part D), 34483465.

Gelman, A. J. (2006), Prior distributions for variance parameters in hierarchical models (Comment on Article by Browne and Draper), Bayesian Analysis, 1(3), 515-534.

Gelman, A. J., J. B. Carlin, H. S. Stern, and D. B. Rubin (2004), Bayesian Data Analysis, Chapman \& Hall/CRC, Boca Raton, Florida.

Grannemann, N. G., R. J. Hunt, J. R. Nicholas, T. E. Reilly, and T. C. Winter (2000), The importance of ground water in the Great Lakes, Tech. rep., US Geological Survey, Lansing, Michigan.

Gronewold, A. D., and V. Fortin (2012), Advancing Great Lakes hydrological science through targeted binational collaborative research, Bulletin of the American Meteorological Society, 93(12), 1921-1925. 
Gronewold, A. D., and C. A. Stow (2014a), Water loss from the Great Lakes, Science, 343(6175), 1084-1085.

Gronewold, A. D., and C. A. Stow (2014b), Unprecedented seasonal water level dynamics on one of the Earth's largest lakes, Bulletin of the American Meteorological Society, $95(1), 15-17$.

Gronewold, A. D., V. Fortin, B. M. Lofgren, A. H. Clites, C. A. Stow, and F. H. Quinn (2013a), Coasts, water levels, and climate change: A Great Lakes perspective, Climatic Change, 120(4), 697-711.

Gronewold, A. D., C. A. Stow, J. L. Crooks, and T. S. Hunter (2013b), Quantifying parameter uncertainty and assessing the skill of exponential dispersion rainfall simulation models, International Journal of Climatology, 33(3), 746-757, doi:10.1002/joc.3469.

Gronewold, A. D., A. H. Clites, J. Bruxer, K. Kompoltowicz, J. P. Smith, T. S. Hunter, and C.Wong (2015), Water levels surge on Great Lakes, Eos, Transactions American Geophysical Union, 96(6), 14-17.

Holcombe, T. L., L. A. Taylor, D. F. Reid, J. S. Warren, P. A. Vincent, and C. E. Herdendorf (2003), Revised Lake Erie postglacial lake level history based on new detailed bathymetry, Journal of Great Lakes Research, 29(4), 681-704.

Holman, K. D., A. D. Gronewold, M. Notaro, and A. Zarrin (2012), Improving historical precipitation estimates over the Lake Superior basin, Geophysical Research Letters, $39(3), \mathrm{L} 03,405$.

Hunter, T. S., A. H. Clites, K. B. Campbell, and A. D. Gronewold (2015), Development and application of a monthly hydrometeorological database for the North American Great Lakes - Part I: precipitation, evaporation, runoff, and air temperature, Journal 
of Great Lakes Research, 41(1), 65-77.

Husak, G. J., J. Michaelsen, and C. Funk (2007), Use of the gamma distribution to represent monthly rainfall in Africa for drough monitoring applications, International Journal of Climatology, 27(7), 935-944.

Johnston, J. W., E. P. Argyilan, T. A. Thompson, S. J. Baedke, K. Lepper, D. A. Wilcox, S. L. Forman, and T. G. Fisher (2012), A Sault-outlet-referenced mid- to late-Holocene paleohydrogrpah for Lake Superior constructed from strandplains of beach ridges, Canadian Journal of Earth Sciences, 49(11), 1263-1279.

Kebede, S., Y. Travi, T. Alemayehu, and V. Marc (2006), Water balance of Lake Tana and its sensitivity to fluctuations in rainfall, Blue Nile basin, Ethiopia, Journal of Hydrology, $316,233-247$.

Lee, D. H., F. H. Quinn, D. Sparks, and J. C. Rassam (1994), Modification of Great Lakes regulation plans for simulation of maximum Lake Ontario outflows, Journal of Great Lakes Research, 20(3), 569-582.

Lenters, J. D. (2001), Long-term trends in the seasonal cycle of Great Lakes water levels, Journal of Great Lakes Research, 27(3), 342-353.

Lofgren, B. M., F. H. Quinn, A. H. Clites, R. A. Assel, A. J. Eberhardt, and C. L. Luukkonen (2002), Evaluation of potential impacts on Great Lakes water resources based on climate scenarios of two GCMs, Journal of Great Lakes Research, 28(4), 537554.

Lofgren, B. M., A. D. Gronewold, A. Acciaioli, J. Cherry, A. L. Steiner, and D. W. Watkins (2013), Methodological approaches to projecting the hydrologic impacts of climate change, Earth Interactions, 17(22), 1-19. 
Lunn, D. J., A. Thomas, N. Best, and D. Spiegelhalter (2000), WinBUGS-A Bayesian modelling framework: Concepts, structure, and extensibility, Statistics and Computing, $10(4), 325-337$.

Lunn, D. J., D. J. Spiegelhalter, A. Thomas, and N. G. Best (2009), The BUGS project: Evolution, critique and future directions, Statistics in Medicine, 28(25), 3049 - 3067.

Mahfouf, J.-F., B. Brasnett, and S. Gagnon (2007), A Canadian precipitation analysis (CaPA) project: Description and preliminary results, Atmosphere-Ocean, 45(1), 1-17.

Mainville, A., and M. R. Craymer (2005), Present-day tilting of the Great Lakes region based on water level gauges, Geological Society of America Bulletin, 117(7), 1070-1080.

McPhaden, M. J. (1999), Genesis and evolution of the 1997-98 El Niño, Science, $283(5404), 950-954$.

Mesinger, F., G. DiMego, E. Kalnay, K. Mitchell, P. C. Shafran, W. Ebisuzaki, D. Jovic, J. Woollen, E. Rogers, E. H. Berbery, M. B. Ek, Y. Fan, R. Grumbine, W. Higgins, H. Li, Y. Lin, G. Manikin, D. Parrish, and W. Shi (2006), North American regional reanalysis, Bulletin of the American Meteorological Society, 87(3), 343-360.

Millerd, F. (2010), The potential impact of climate change on Great Lakes international shipping, Climatic Change, 104, 629-652.

NOAA National Climatic Data Center (2014), State of the climate: synoptic discussion for January 2014, Tech. rep.

Notaro, M., W. C. Wang, and W. Gong (2006), Model and observational analysis of the Northeast U. S. regional climate and its relationship to the PNA and NAO patterns during early winter, Monthly Weather Review, 134(11), 3479-3505. 
Obenour, D. R., A. D. Gronewold, C. A. Stow, and D. Scavia (2014), Using a Bayesian hierarchical model to improve Lake Erie cyanobacteria bloom forecasts, Water Resources Research, 50(10), 7847-7860.

Piccolroaz, S., M. Toffolon, and B. Majone (2015), The role of stratification on lakes' thermal response: The case of Lake Superior, Water Resources Research, 51, doi: 10.1002/2014WR016555.

Pietroniro, A., V. Fortin, N. Kouwen, C. Neal, R. Turcotte, B. Davison, D. Verseghy, E. D. Soulis, R. Caldwell, and N. Evora (2007), Development of the MESH modelling system for hydrological ensemble forecasting of the Laurentian Great Lakes at the regional scale, Hydrology and Earth System Sciences, 11(4), 1279-1294.

Plummer, M. (2003), JAGS: A program for analysis of Bayesian graphical models using Gibbs sampling, in Proceedings of the 3rd international workshop on distributed statistical computing, p. 125, Technische Universit at Wien.

Press, S. J. (2003), Subjective and Objective Bayesian Statistics: Principles, Models, and Applications, Wiley-Interscience, Hoboken, NJ.

Qian, S. S., and C. J. Richardson (1997), Estimating the long-term phosphorus accretion rate in the Everglades: A Bayesian approach with risk assessment, Water Resources Research, 33(7), 1681-1688.

Qian, S. S., C. A. Stow, and M. E. Borsuk (2003), On Monte Carlo methods for Bayesian inference, Ecological Modelling, 159(2-3), 269-277, doi:10.1016/S0304-3800(02)00299-5.

Quinn, F. H. (1979), An improved aerodynamic evaporation technique for large lakes with application to the International Field Year for the Great Lakes, Water Resources Research, 15(4), 935-940. 
Quinn, F. H. (1985), Temporal effects of St. Clair River dredging on Lakes St. Clair and Erie water levels and connecting channel flow, Journal of Great Lakes Research, $11(3)$, 400-403.

Quinn, F. H. (2002), Secular changes in Great Lakes water level seasonal cycles, Journal of Great Lakes Research, 28(3), 451-465.

Quinn, F. H., and J. Edstrom (2000), Great Lakes diversions and other removals, Canadian Water Resources Journal, 25(2), 125-151.

Quinn, F.H., and B. Guerra (1986), Current perspectives on the Lake Erie water balance, Journal of Great Lakes Research, 12(2), 109-116.

Quinn, F. H., and C. E. Sellinger (2006), A reconstruction of Lake Michigan-Huron water levels derived from tree ring chronologies for the period 1600-1961, Journal of Great Lakes Research, 32(1), 29-39.

Read, J., V. Klump, T. H. Johengen, D. J. Schwab, K. Paige, E. Stuart, E. J. Anderson, and C. Mannien (2010), Working in freshwater: The Great Lakes observing system contributes to regional and national observations, data infrastructure, and decision support, Marine Technology Society Journal, 44(6), 84-98.

Reckhow, K. H., and S. C. Chapra (1983), Confirmation of water quality models, Ecological Modelling, 20(2-3), 113-133.

Spence, C., P. D. Blanken, N. Hedstrom, V. Fortin, and H. Wilson (2011), Evaporation from Lake Superior: 2: Spatial distribution and variability, Journal of Great Lakes Research, $37(4), 717-724$.

Spence, C., P. D. Blanken, J. D. Lenters, and N. Hedstrom (2013), The importance of spring and autumn atmospheric conditions for the evaporation regime of Lake Superior, 
Journal of Hydrometeorology, 14(5), 1647-1658.

Stakhiv, E. Z. (2011), Pragmatic approaches for water management under climate change uncertainty, Journal of the American Water Resources Association, 47(6), 1183-1196.

Swenson, S., and J. Wahr (2009), Monitoring the water balance of Lake Victoria, East Africa, from space, Journal of Hydrology, 370, 163-176.

Thom, H. C. (1958), A note on the gamma distribution, Monthly Weather Review, 86(4), $117-122$.

Van Cleave, K., J. D. Lenters, J. Wang, and E. M. Verhamme (2014), A regime shift in Lake Superior ice cover, evaporation, and water temperature following the warm El Niño winter of 1997-1998, Limnology and Oceanography, 59(6), 1889-1898.

Watkins, D. W., H. Li, and J. R. Cowden (2007), Adjustment of radar-based precipitation estimates for Great Lakes hydrological modeling, Journal of Hydrologic Engineering, $12(3), 298-305$.

Watras, C. J., J. S. Read, K. D. Holman, Z. Liu, Y. Y. Song, A. J. Watras, S. Morgan, and E. H. Stanley (2014), Decadal oscillation of lakes and aquifers in the upper Great Lakes region of North America: Hydroclimatic implications, Geophysical Research Letters, $41(2), 456-462$.

Wiles, G. C., A. C. Krawiec, and R. D. D’Arrigo (2009), A 265-year reconstruction of Lake Erie water levels based on North Pacific tree rings, Geophysical Research Letters, $36(5)$. 


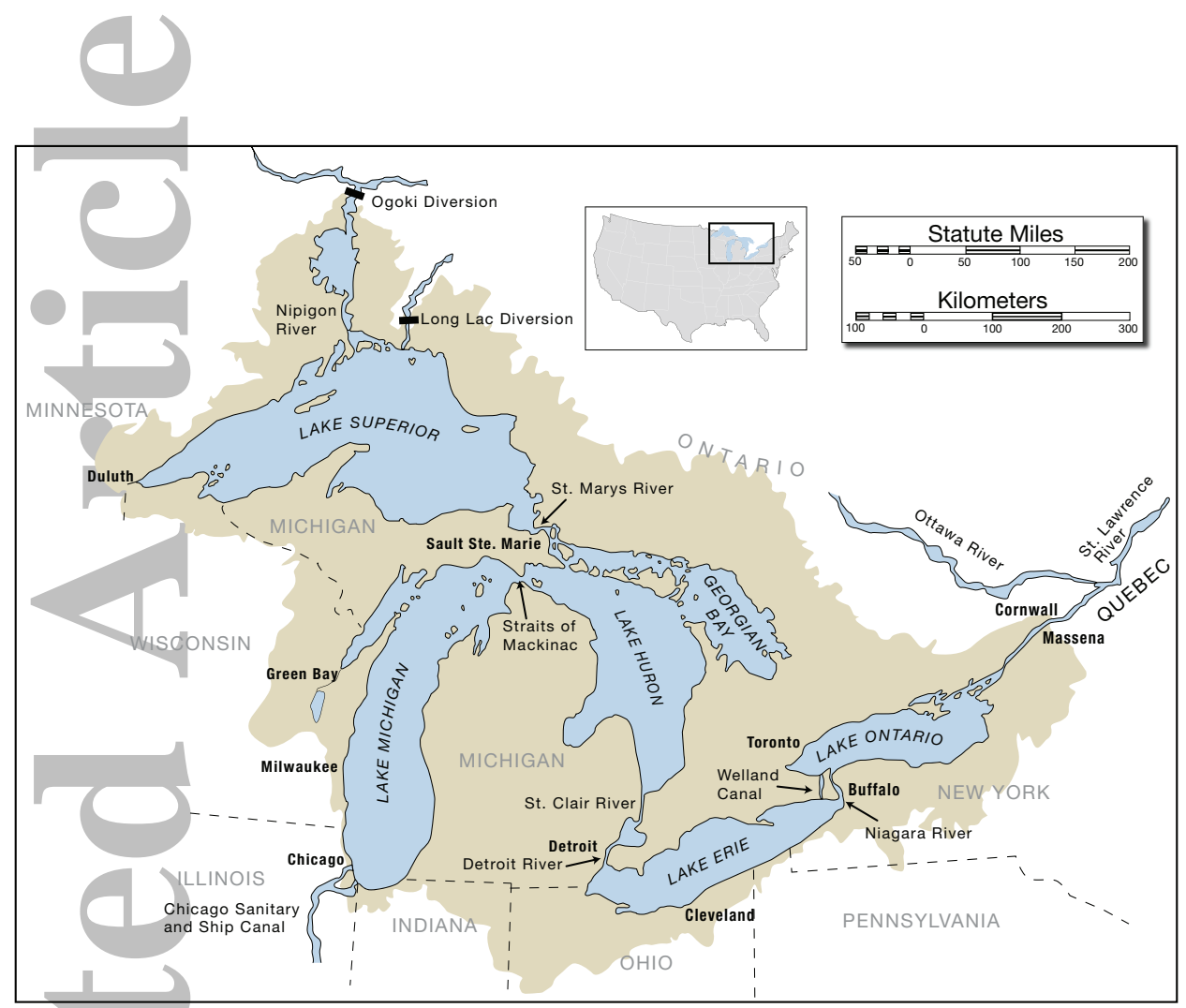

Figure 1. Map of the North American Great Lakes drainage basin including major cities, political boundaries, interbasin diversions, and interconnecting channels.

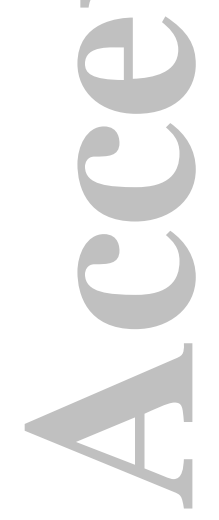



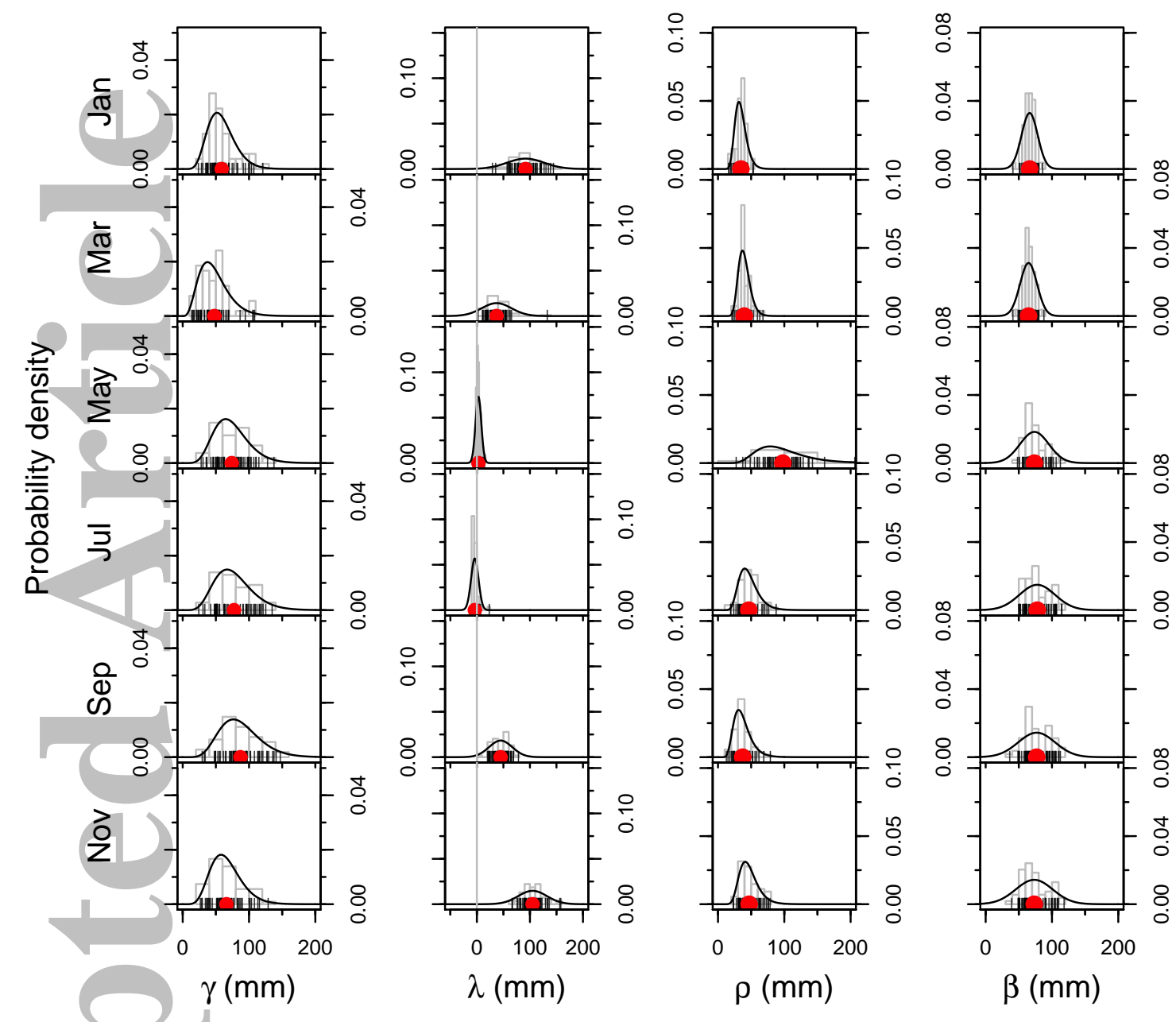

Figure 2. Development of prior probability distributions for Lake Superior monthly water budget components. Plot includes every other month (starting in January) for clarity and simplicity. Prior probability distributions for all months for both Lakes $\underline{\text { Superior and Michigan-Huron are included in supporting information figures S1 and S2. }}{ }^{11}$. Vertical tick marks along $\mathrm{x}$-axis and histograms in each panel are based on values from the historical record from 1950 to 2004 in the GLM-HMD [Hunter et al., 2015]. Red dots represent the historical mean, and thin black curves represent the "fitted" prior probability distributions. 
Figure 3. Evolution of posterior probability distributions for Lake Superior monthly $\underline{\text { water budget components in 2014. Figure includes every other month starting in January }}$ for clarity and simplicity. Posterior probability distributions for all months of 2014 for $\underline{\text { both Lakes Superior and Michigan-Huron are included in supporting information figures }}$ $\underline{\mathrm{S} 3}$ and $\mathrm{S} 4^{18}$. In all panels, thin black curves represent prior probability distributions (from figure 2) and dark grey curves represent posterior probability distributions. Blue curves (in two left-most columns for over-lake precipitation and over-lake evaporation) represent likelihood functions from GEM models, and red curves (in three left-most columns for over-lake precipitation, over-lake evaporation, and runoff) represent likelihood functions from GLM-HMD. In the right-most column (for flow estimates through the St. Marys River) purple curves represent likelihood functions from international gaging station estimates, and green curves represent likelihood functions from internationally-coordinated estimates.

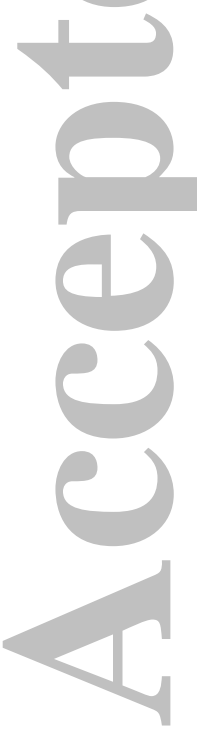



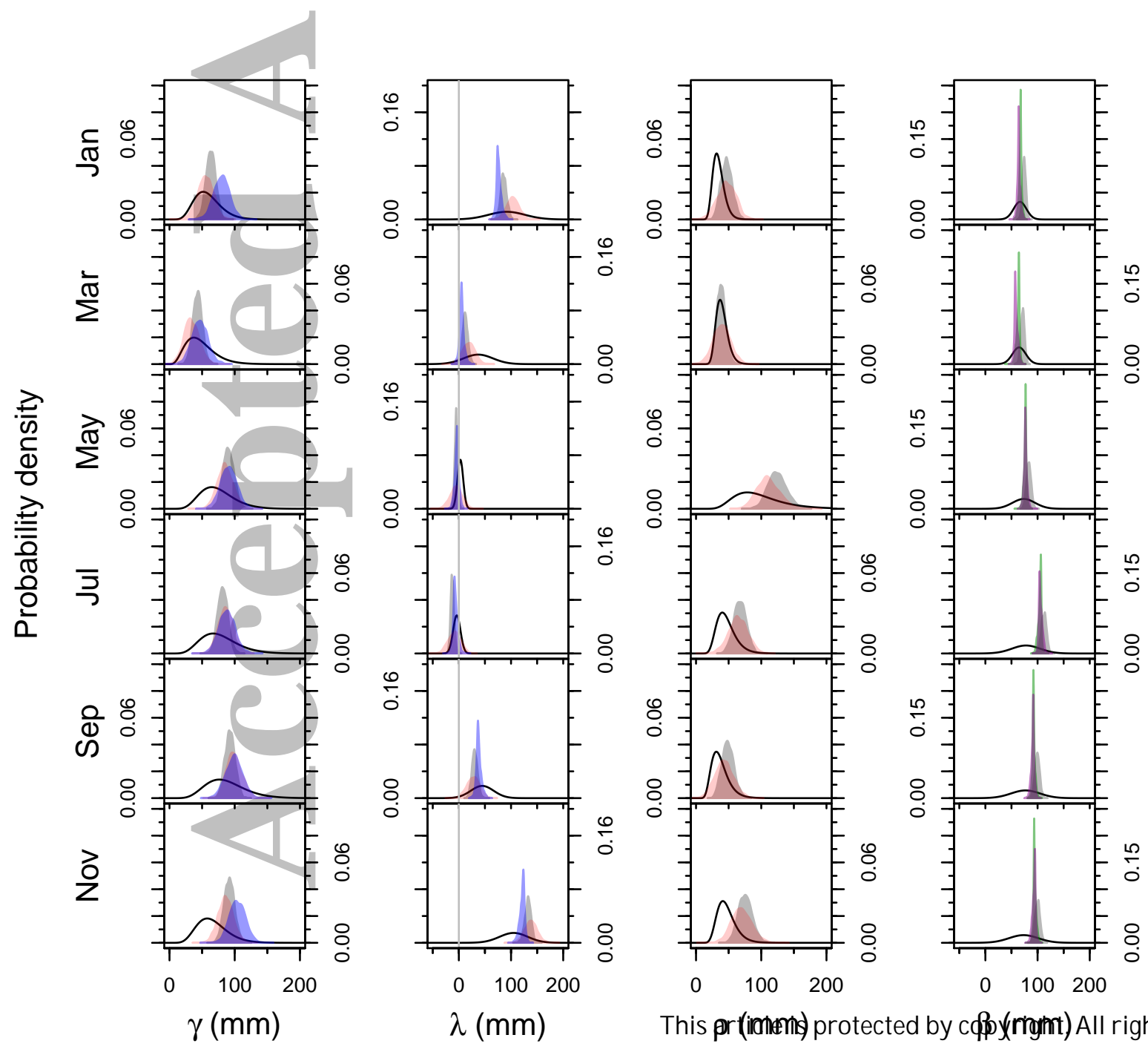

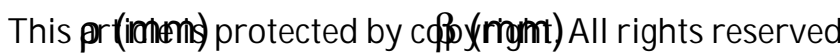




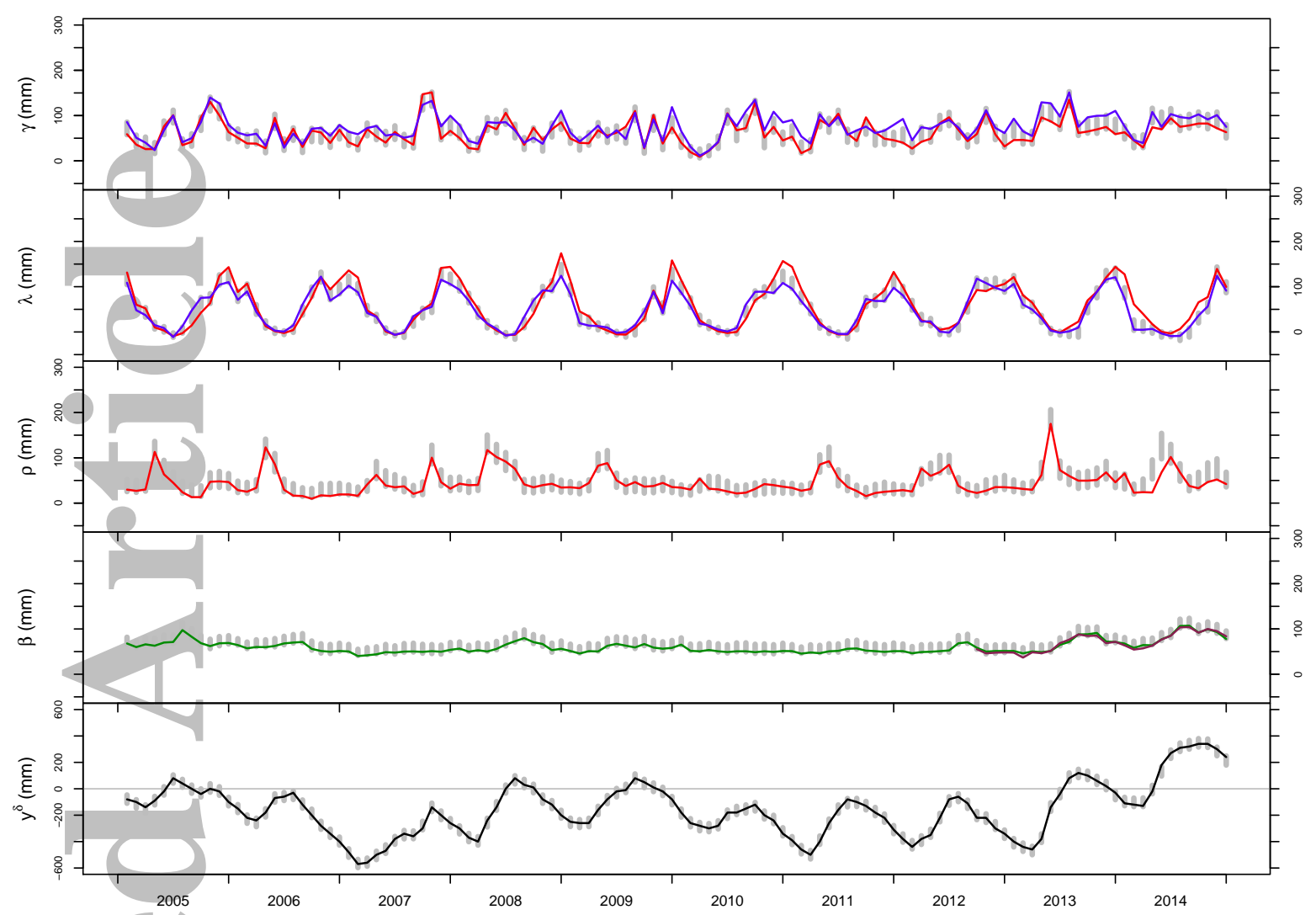

Figure 4. Time series of Lake Superior monthly water budget components from (1)

2005 through 2014. Blue and red lines in the top three panels represent, respectively, estimates from the GEM modeling system and GLM-HMD. Green lines and purple lines in the fourth panel (from top) represent, respectively, internationally-coordinated channel outflow estimates and the estimates from the new international gauging stations. The black line in the bottom panel represents the observed water level at the end of each month relative to the January 2005 BOM water level. Grey vertical bars in the top four panels represent $95 \%$ credible intervals from the posterior probability distribution of our new estimates, and grey vertical bars in the bottom panel represent $95 \%$ intervals from the posterior predictive distribution for the observed net change in water level. 


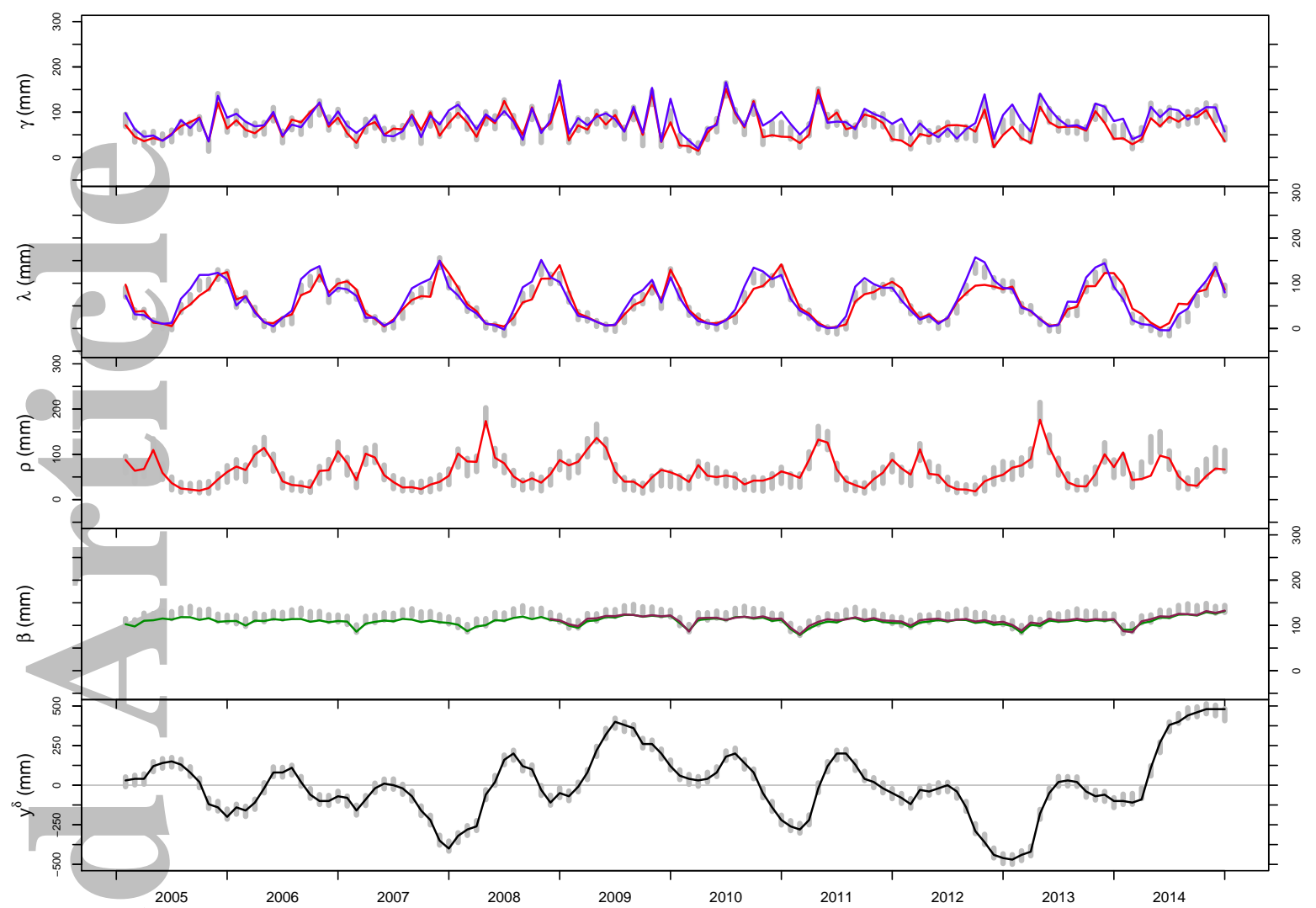

Figure 5. Time series of Lake Michigan-Huron monthly water budget components from 2005 through 2014. Blue and red lines in the top three panels represent, respectively, estimates from the GEM modeling system and GLM-HMD. Green lines and purple lines in the fourth panel (from top) represent, respectively, internationally-coordinated channel outflow estimates and the estimates from the new international gauging stations. The black line in the bottom panel represents the observed water level at the end of each month relative to the January 2005 BOM water level. Grey vertical bars in the top four panels represent $95 \%$ credible intervals from the posterior probability distribution of our new estimates, and grey vertical bars in the bottom panel represent $95 \%$ intervals from the posterior predictive distribution for the observed net change in water level. 


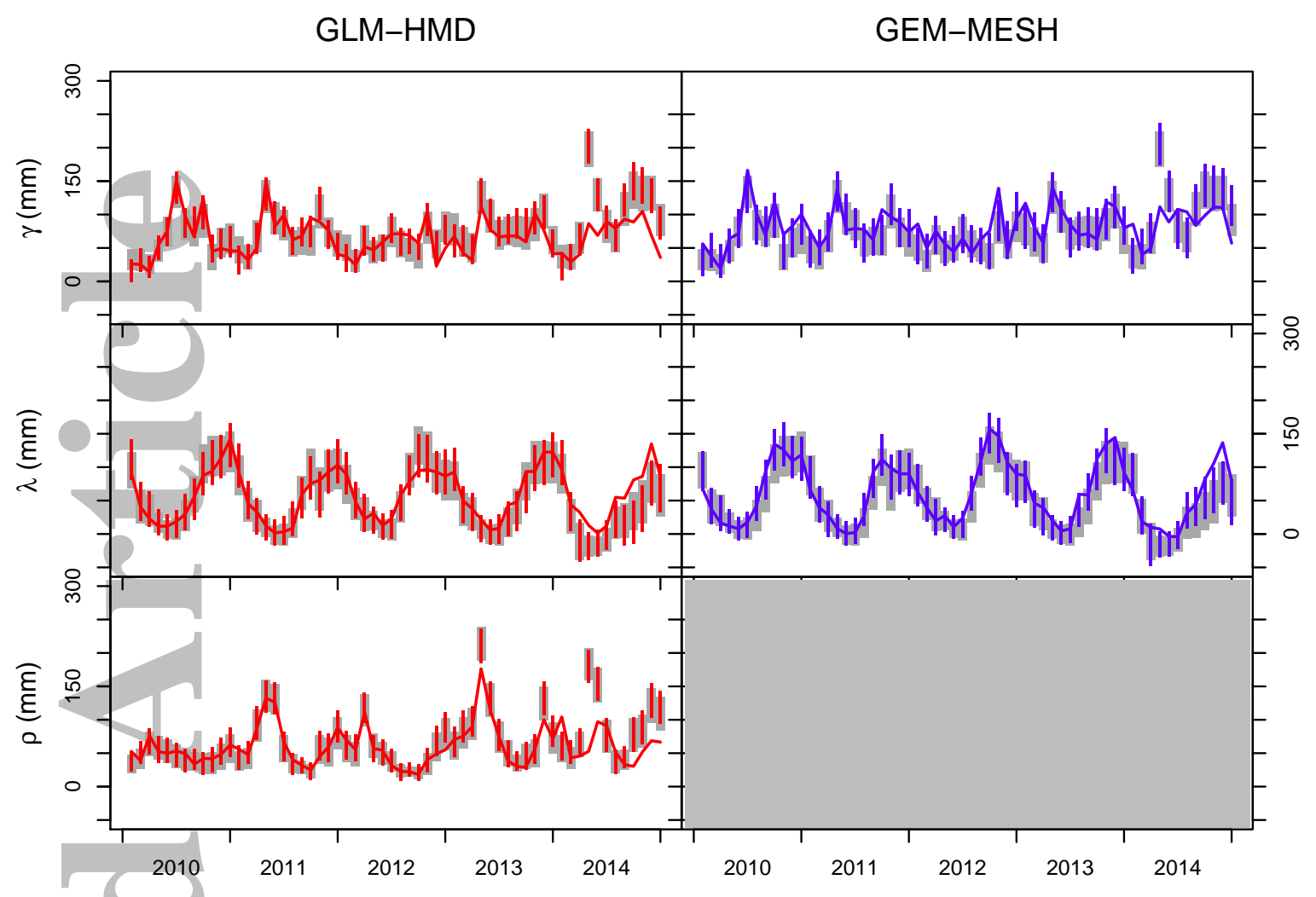

Figure 6. Model validation results, including time series of posterior distribution for water budget components (95\% credible intervals represented by vertical grey bars), posterior predictive distribution for GLM-HMD and GEM-MESH estimates (95\% intervals represented by vertical blue and red bars), and GLM-HMD and GEM-MESH estimates (continuous red and blue lines). As described in our validation methodology, results in each panel (i.e. for the 2010 through 2014 time period) were inferred without using the GLM-HMD and GEM-MESH estimates from the same time period. ${ }^{21}$ 


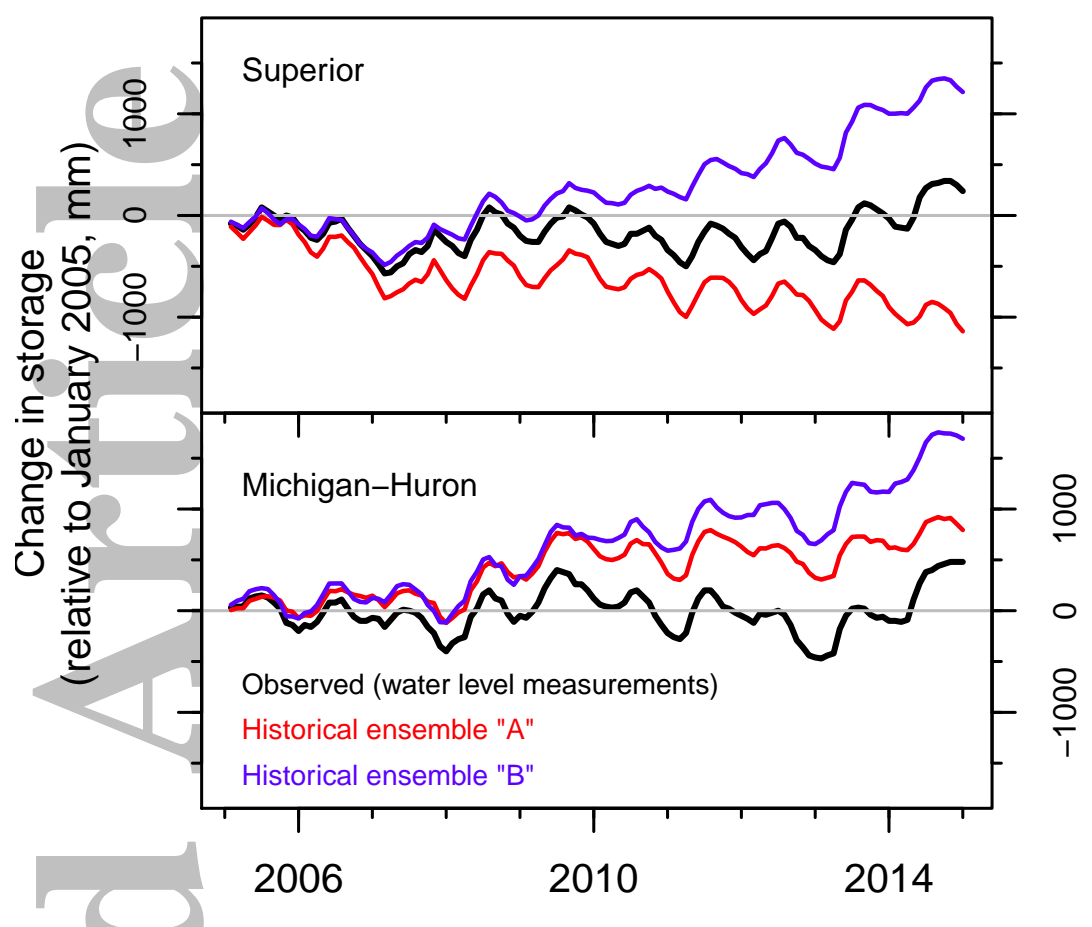

Figure 7. Comparison between changes in lake storage relative to January 2004 $\underline{\text { based on water level observations (black lines), and two ensembles ("A" and "B") }}$ $\underline{\text { based on combinations of estimates from GLM-HMD, GEM, and ICF (red and blue }}$ lines). Specifically, ensemble "A" (red line) is based on GLM-HMD estimates of $\gamma$, $\underline{\lambda \text {, and } \rho \text {, and internationally-coordinated (i.e. ICF) estimates of } \alpha \text { and } \beta \text {. Ensemble }}$ "B" (blue line) is based on GEM estimates of $\gamma$ and $\lambda$, GLM-HMD estimates of $\rho$, and internationally-coordinated estimates of $\alpha$ and $\beta^{24}$ 


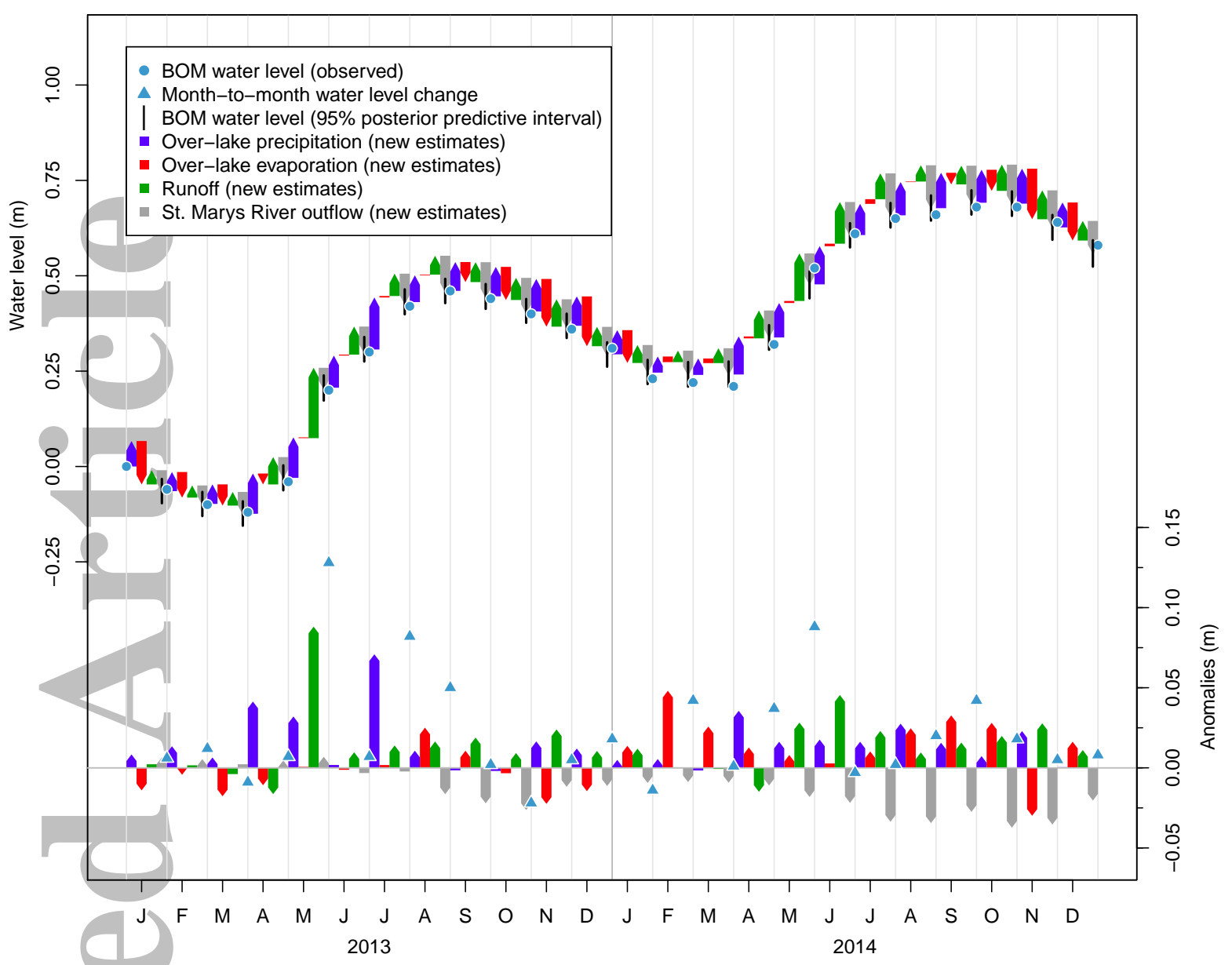

Figure 8. Month-by-month analysis of our new water budget component estimates for Lake Superior. In top portion of plot, BOM water levels and water budget components are plotted relative to January 2013 BOM water levels. The height of each arrow reflects the magnitude of the corresponding water budget component for that month. Moving left to right across each month, the "base" of each arrow aligns with the tip of the arrow from the previous (i.e. to the left) water budget component. Vertical black bars aligned with the arrow representing monthly outflow reflect the $95 \%$ posterior predictive interval for BOM water levels. The bottom portion of the plot represents anomalies in each monthly $\underline{\text { water level differential and each monthly water budget component relative to the } 2005}$

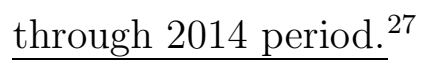




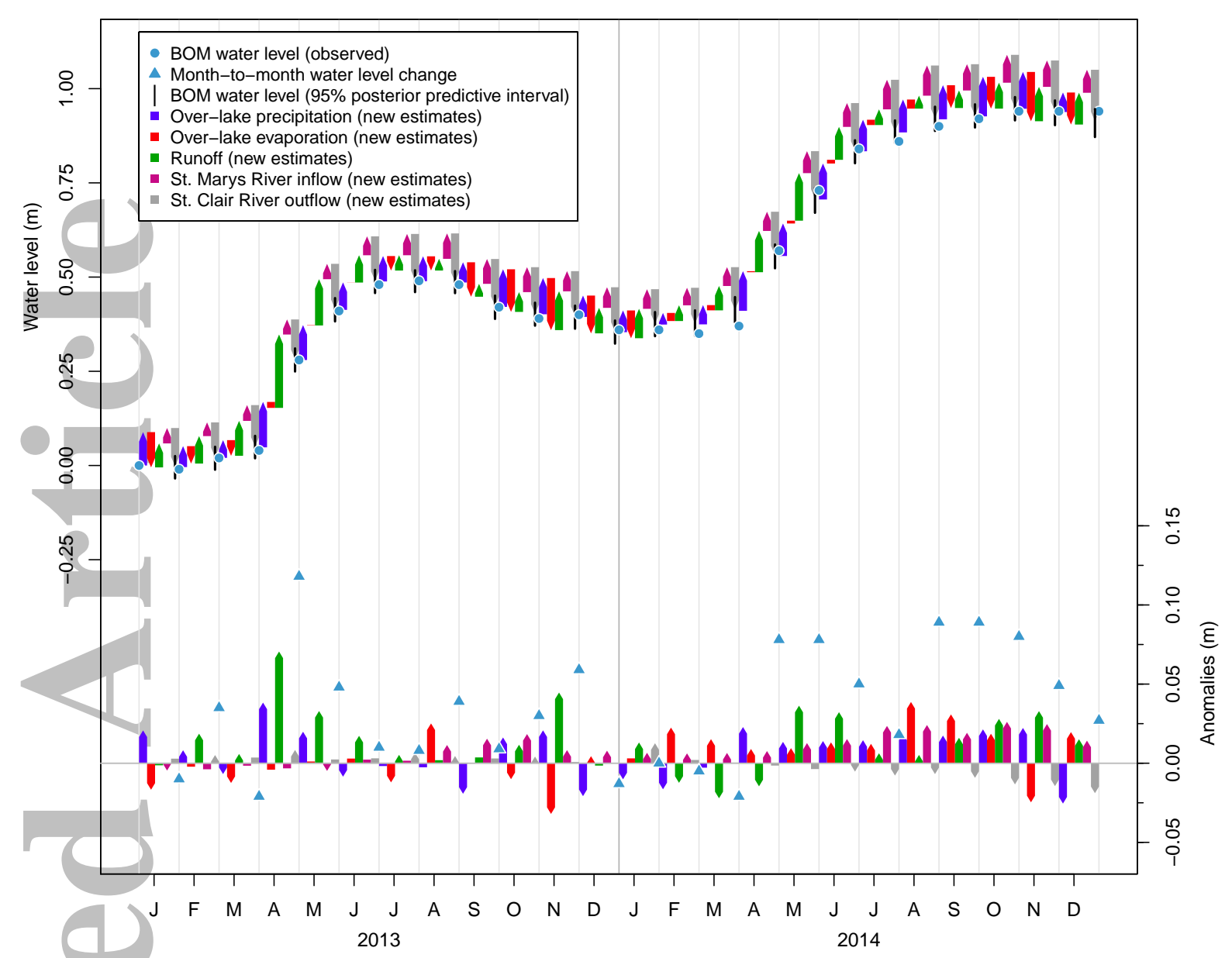

Figure 9. Month-by-month analysis of our new water budget component estimates for Lake Michigan-Huron. In top portion of plot, BOM water levels and water budget components are plotted relative to January 2013 BOM water levels. The height of each arrow reflects the magnitude of the corresponding water budget component for that month. Moving left to right across each month, the "base" of each arrow aligns with the tip of the arrow from the previous (i.e. to the left) water budget component. Vertical black bars aligned with the arrow representing monthly outflow reflect the $95 \%$ posterior predictive interval for BOM water levels. The bottom portion of the plot represents anomalies in $\underline{\text { each monthly water level differential and each monthly water budget component relative }}$

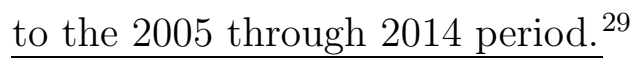




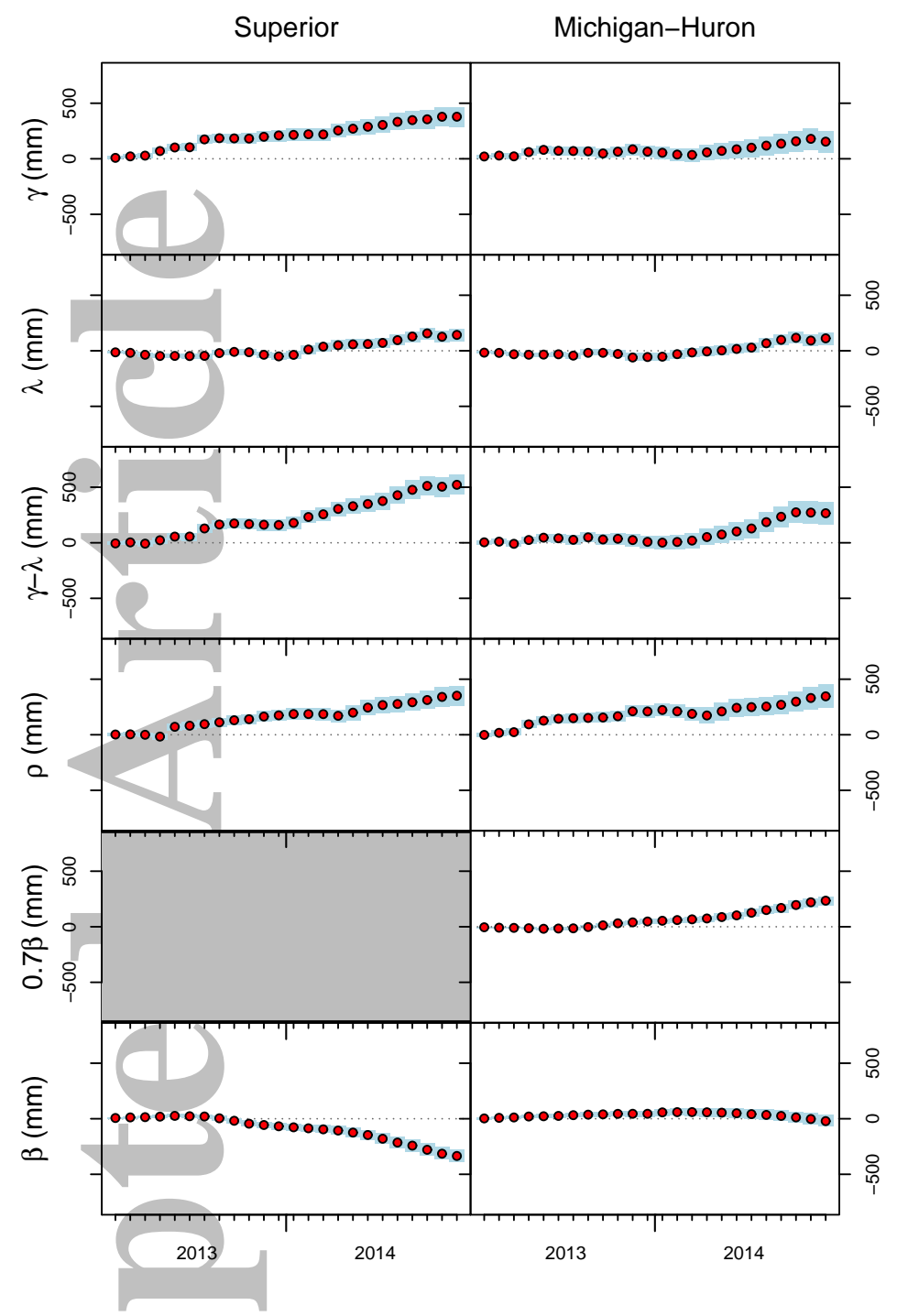

Figure 10. Mean (red dot) and $95 \%$ credible interval (vertical blue bars) of cumulative water budget anomalies (relative to averages from 2005 through 2014) for Lake Superior (left column) and Lake Michigan-Huron (right column). Components include over-lake precipitation (first row), over-lake evaporation (second row), over-lake precipitation minus over-lake evaporation (third row), tributary runoff (fourth row), inflows from the upstream connecting channel (fifth row), and outflows through the downstream connecting channel (bottom row). Components are expressed as depths of water over the surface of each respective lake. Positive cumulative anomalies represent above-average contributions to and below-average losses from the water budget. 

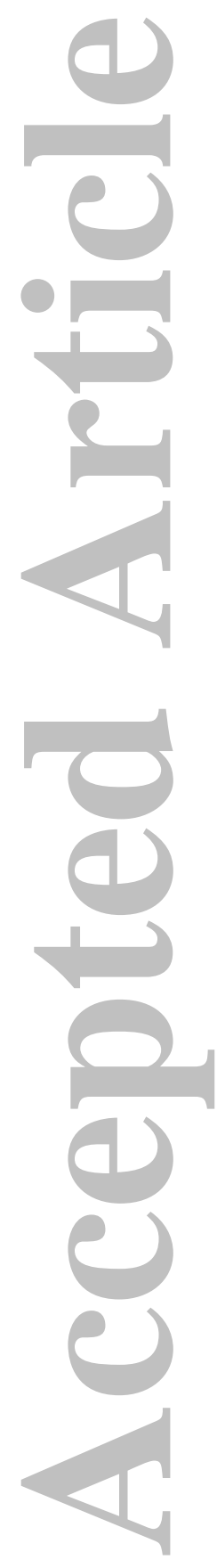
Table 1. Summary of model parameters and variables ${ }^{\mathrm{a}, \mathrm{b}, \mathrm{c}}$

\begin{tabular}{|c|c|}
\hline Symbol & Description \\
\hline \multicolumn{2}{|c|}{ Index variables } \\
\hline \multicolumn{2}{|c|}{$j \quad$ Index for month; $j=1,2, \ldots, J$} \\
\hline \multicolumn{2}{|c|}{$J \quad$ Number of months assessed (for our study $J=120$ ) } \\
\hline \multicolumn{2}{|c|}{ Water balance model parameters } \\
\hline & Cumulative change in lake storage (through end of month) \\
\hline$\gamma$ & Monthly over-lake precipitation \\
\hline & Monthly over-lake evaporation \\
\hline & Monthly lake tributary inflow \\
\hline & Monthly lake inflow through interbasin diversions \\
\hline & Monthly lake outflow through connecting channel \\
\hline & Monthly water balance model error term \\
\hline \multicolumn{2}{|c|}{ Water balance model variables } \\
\hline \multicolumn{2}{|r|}{$y^{\delta} \quad$ Measured (from water level gauges) cumulative change in lake storage through month $j$} \\
\hline \multicolumn{2}{|r|}{$y^{\beta_{1}} \quad$ Internationally-coordinated estimate of connecting channel monthly outflow } \\
\hline \multicolumn{2}{|r|}{ International gauging station-based estimate of connecting channel monthly outflow } \\
\hline \multicolumn{2}{|r|}{ timate of monthly inflow via interbasin diversions (maintained by Coordinating Committee) } \\
\hline \multicolumn{2}{|r|}{$y^{\gamma_{1}} \quad$ Estimate of monthly over-lake precipitation from NOAA-GLERL GLM-HMD } \\
\hline \multicolumn{2}{|r|}{$y^{\lambda_{1}} \quad$ Estimate of monthly over-lake evaporation from NOAA-GLERL GLM-HMD } \\
\hline \multicolumn{2}{|r|}{ Estimate of monthly tributary inflow from NOA } \\
\hline \multicolumn{2}{|r|}{$y^{\gamma_{2}} \quad$ Estimate of monthly over-lake precipitation from GEM system } \\
\hline \multicolumn{2}{|r|}{$y^{\lambda_{2}} \quad$ Estimate of monthly over-lake evaporation from GEM system } \\
\hline \multicolumn{2}{|r|}{$y^{\rho_{2}} \quad$ Estimate of monthly lake tributary inflow from GEM system } \\
\hline \multicolumn{2}{|c|}{ Statistical model symbology } \\
\hline & Prior probability distribution \\
\hline$\tau^{y^{\delta}}$ & Precision of measured cumulative change in storage, $y^{\delta} \sim \operatorname{No}\left(\delta, \tau^{y^{\delta}}\right)$ \\
\hline$\psi^{1}, \psi^{2}$ & Shape and rate of prior probability distribution for $\gamma \sim \mathrm{Ga}\left(\psi^{1}, \psi^{2}\right)$ \\
\hline$\mu^{*}, \tau^{*}$ & Mean, precision of prior probability distributions for $\alpha, \beta, \lambda \sim \operatorname{No}\left(\mu^{*}, \tau^{*}\right)$ \\
\hline$\mu^{\rho}, \tau^{\rho}$ & Log-mean, log-precision of prior probability distribution for $\rho \sim \operatorname{LN}\left(\mu^{\rho}, \tau^{\rho}\right)$ \\
\hline & Inferred mean of water balance parameter $*$ from $y^{* 1} \sim \operatorname{No}\left(\theta^{*_{1}}, \tau^{*_{1}}\right)$ \\
\hline$\theta^{*_{2}}$ & Inferred mean of water balance parameter $*$ from $y^{*_{2}} \sim \operatorname{No}\left(\theta^{*_{2}}, \tau^{*_{2}}\right)$ \\
\hline$\eta_{* 1}^{* 1}, \eta^{* 2}$ & Bias in inferred mean of water balance parameter $*$ from source 1,2 \\
\hline$\tau^{* 1}, \tau^{* 2}$ & Precision of estimate for parameter $*$ from source 1,2 \\
\hline
\end{tabular}

a Water balance model parameters and variables for Lake (S)uperior and Lake (M)ichigan-

Huron are differentiated in either the manuscript text or model code by superscripts $s$ and $m$,

respectively (subscripts removed from table above for simplicity and clarity).

b Unless otherwise indicated, parameters and variables are in units of $\mathrm{mm}$ over the respective

lake surface area.

c Water balance model parameters and variables are indexed (via subscripts) in the manuscript

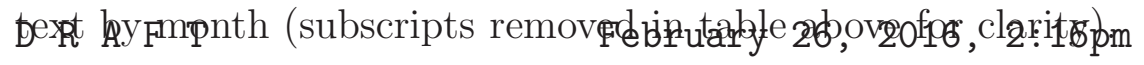

D R A F T 

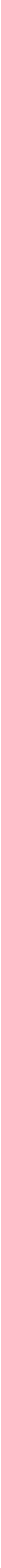

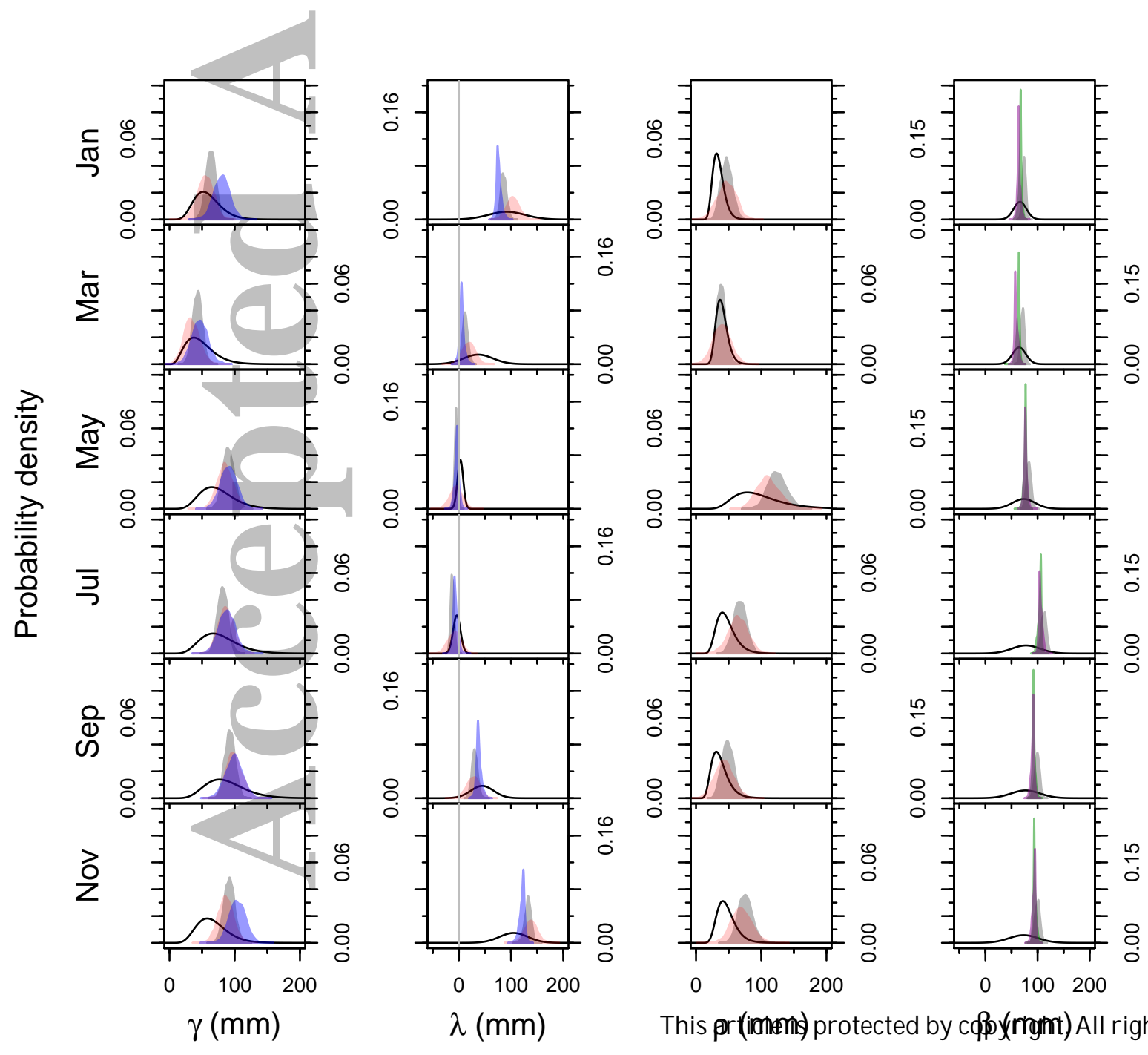

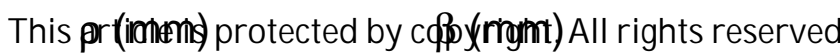




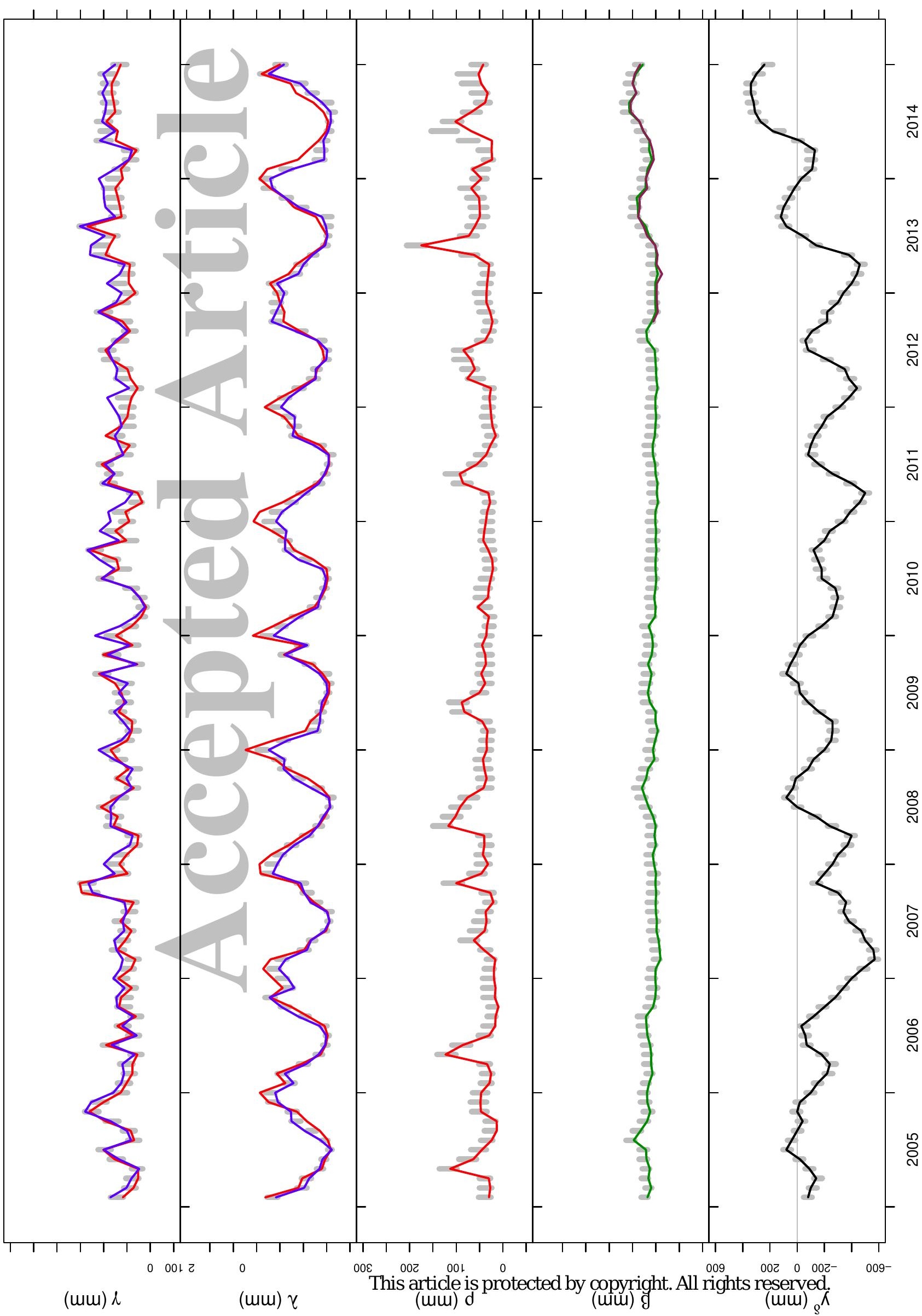




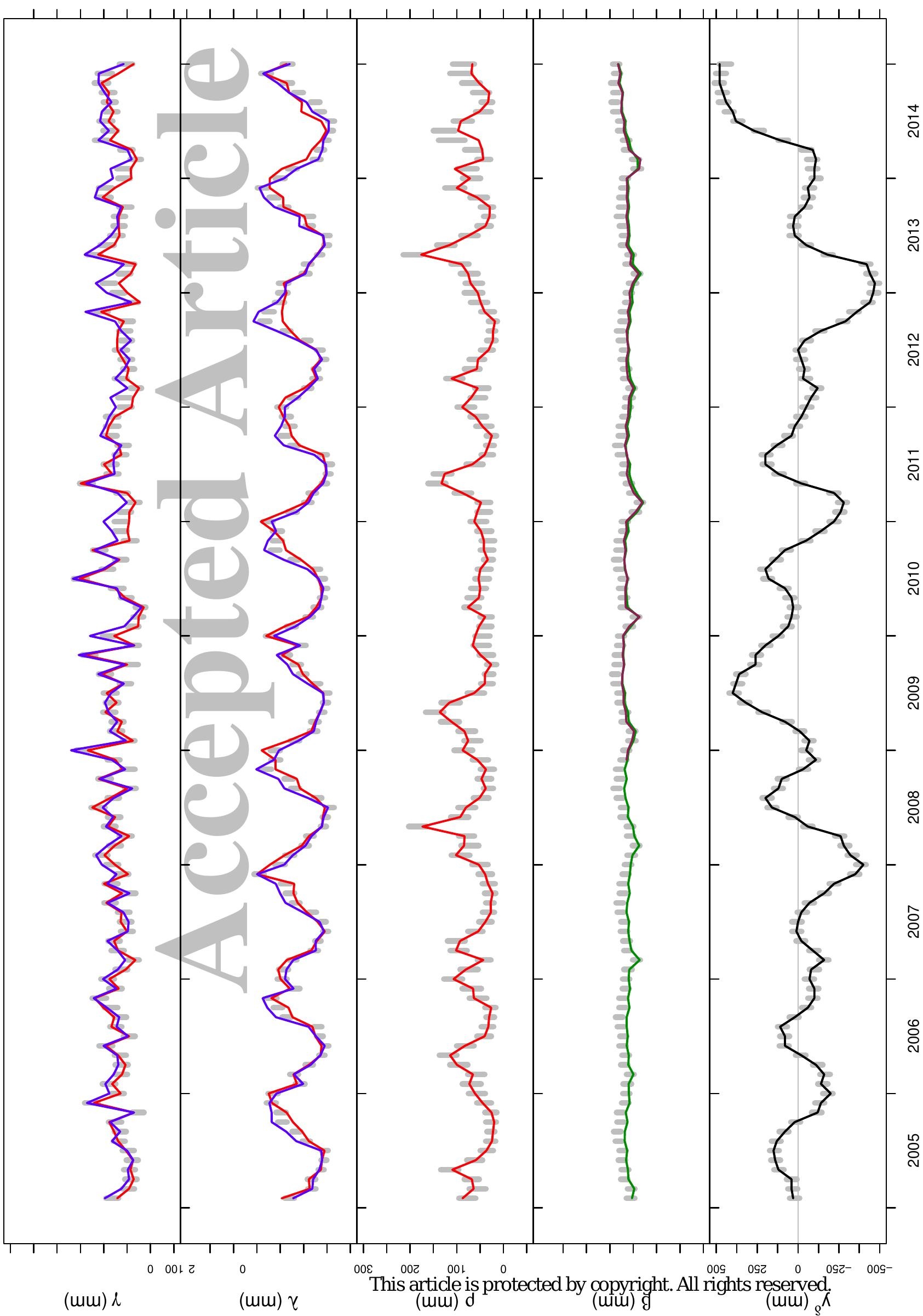




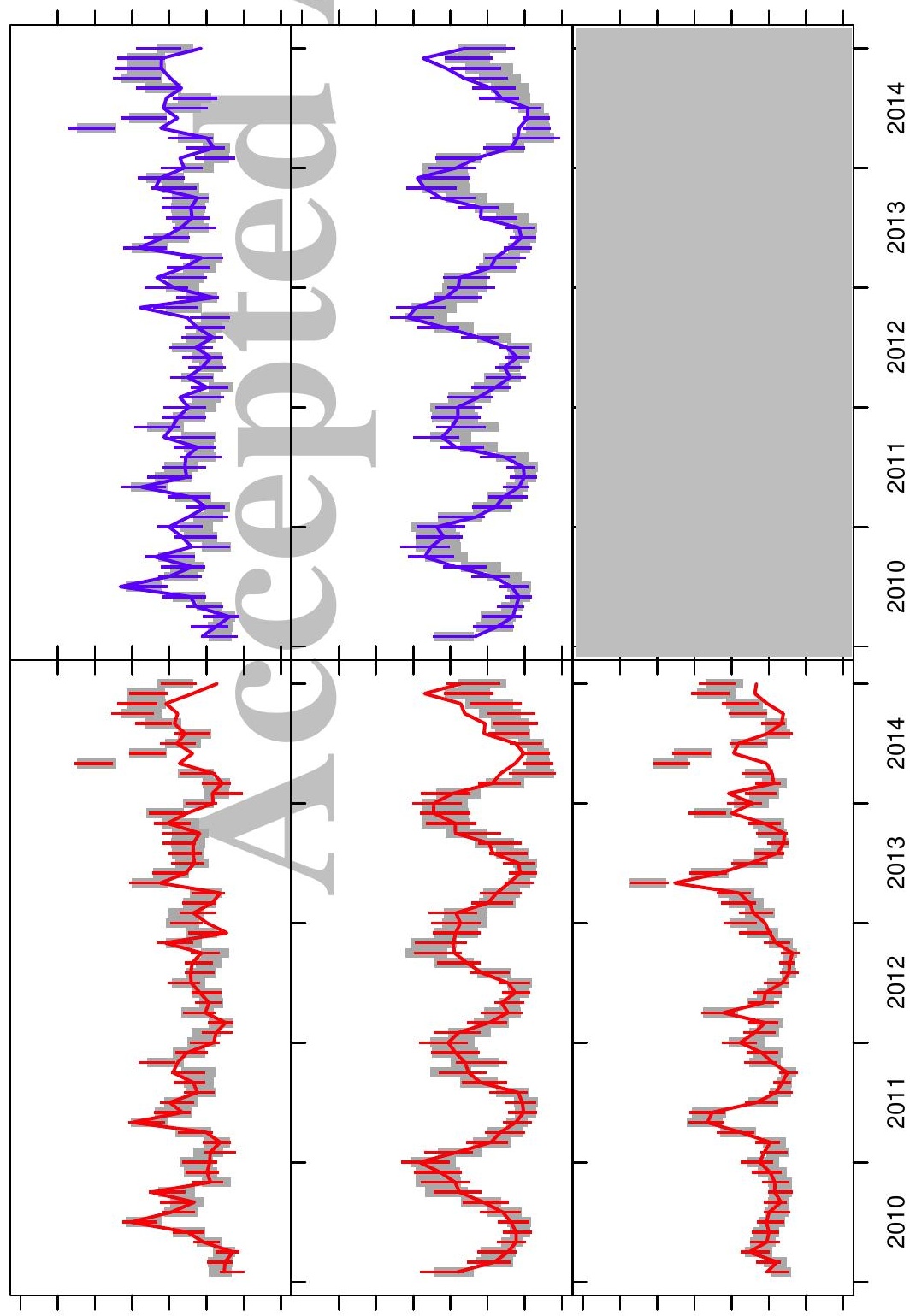
OOE OSเ 0

(mw) $\ell$ 
000 0000 L $^{-}$

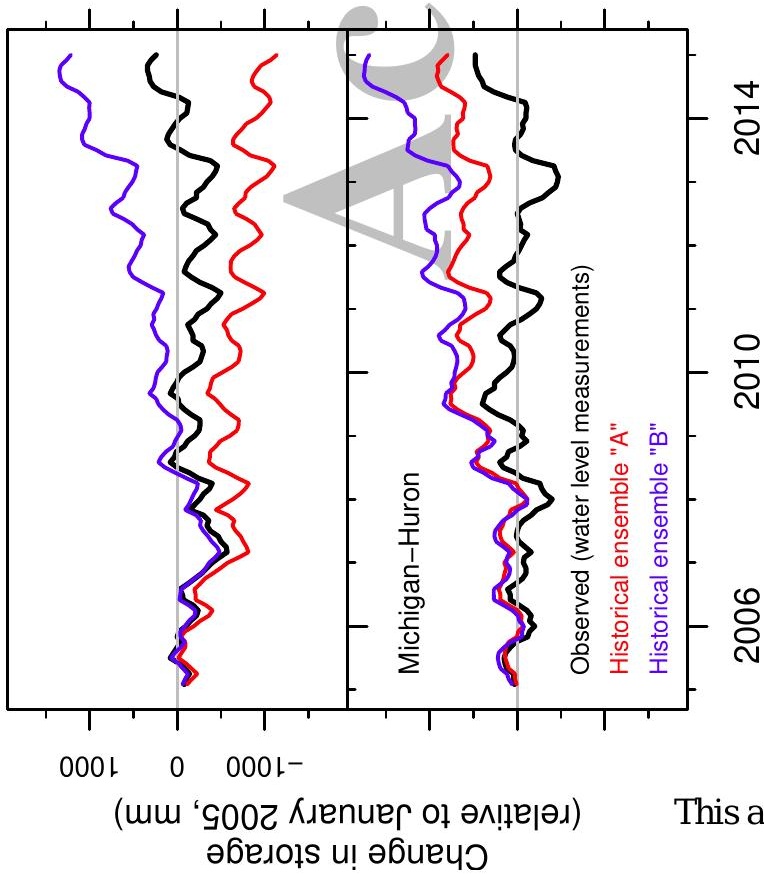


(u) sə!ןemout

S.0 $0 L^{\circ} 0 \quad S 0^{\circ} 0 \quad 00^{\circ} 0 \quad S 0^{\circ} 0^{-}$

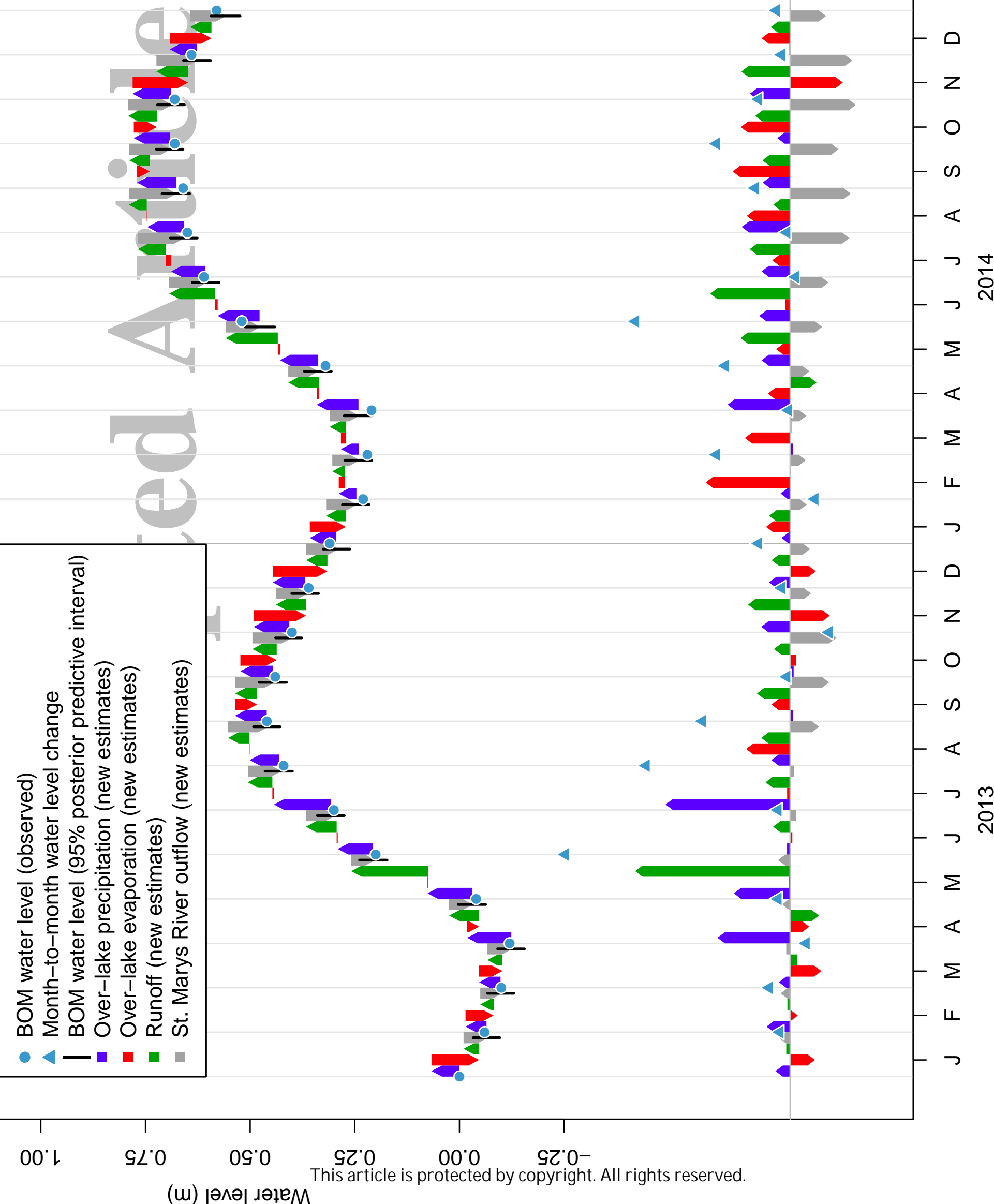


(u) sə!ןemout

S.O $0 L^{\circ} 0 \quad S 0^{\circ} 0 \quad 00^{\circ} 0 \quad S 0^{\circ} 0^{-}$
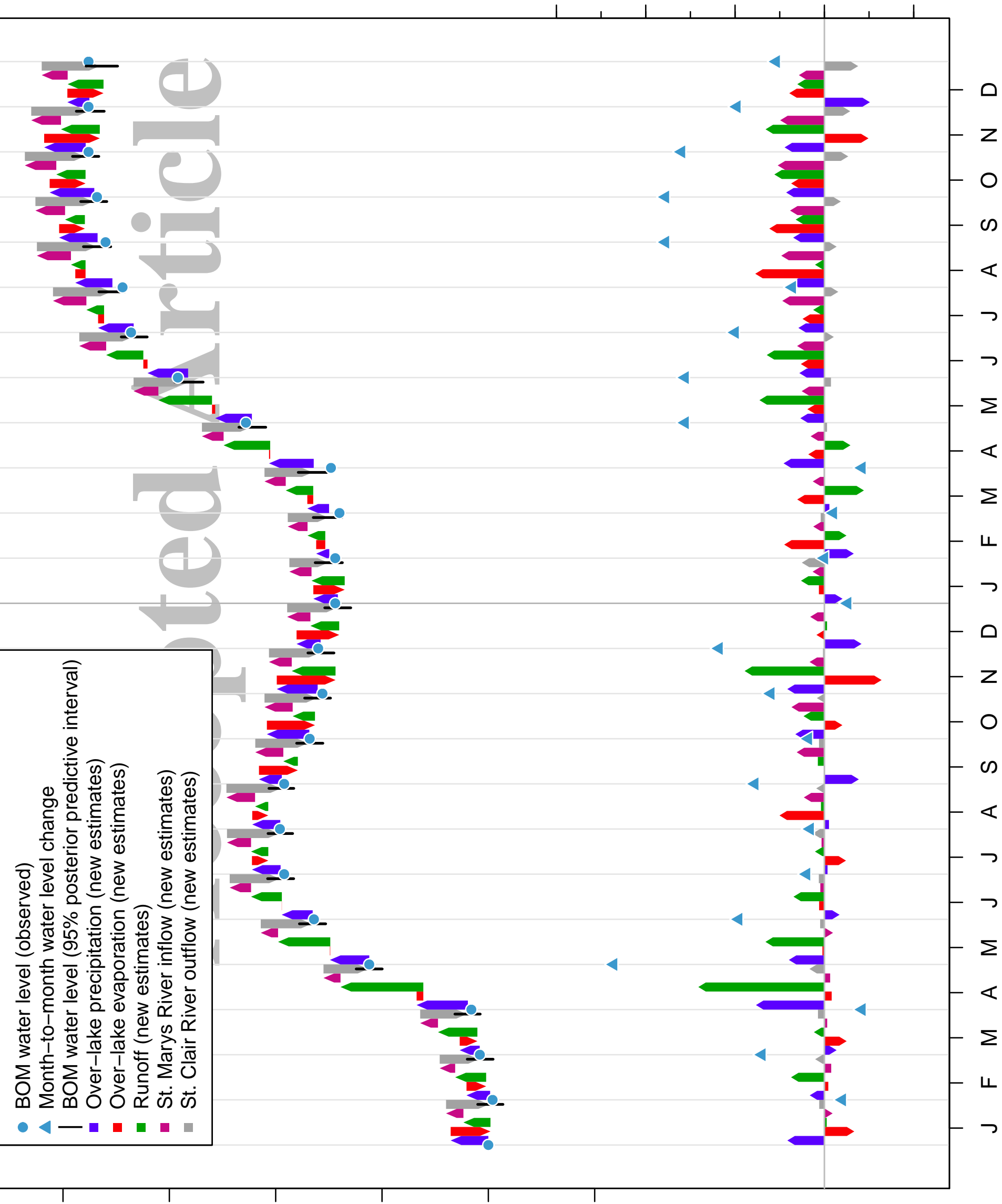

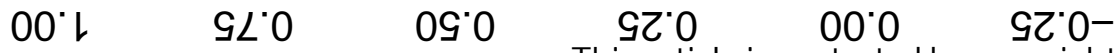

(u) ןәлә дәાем 


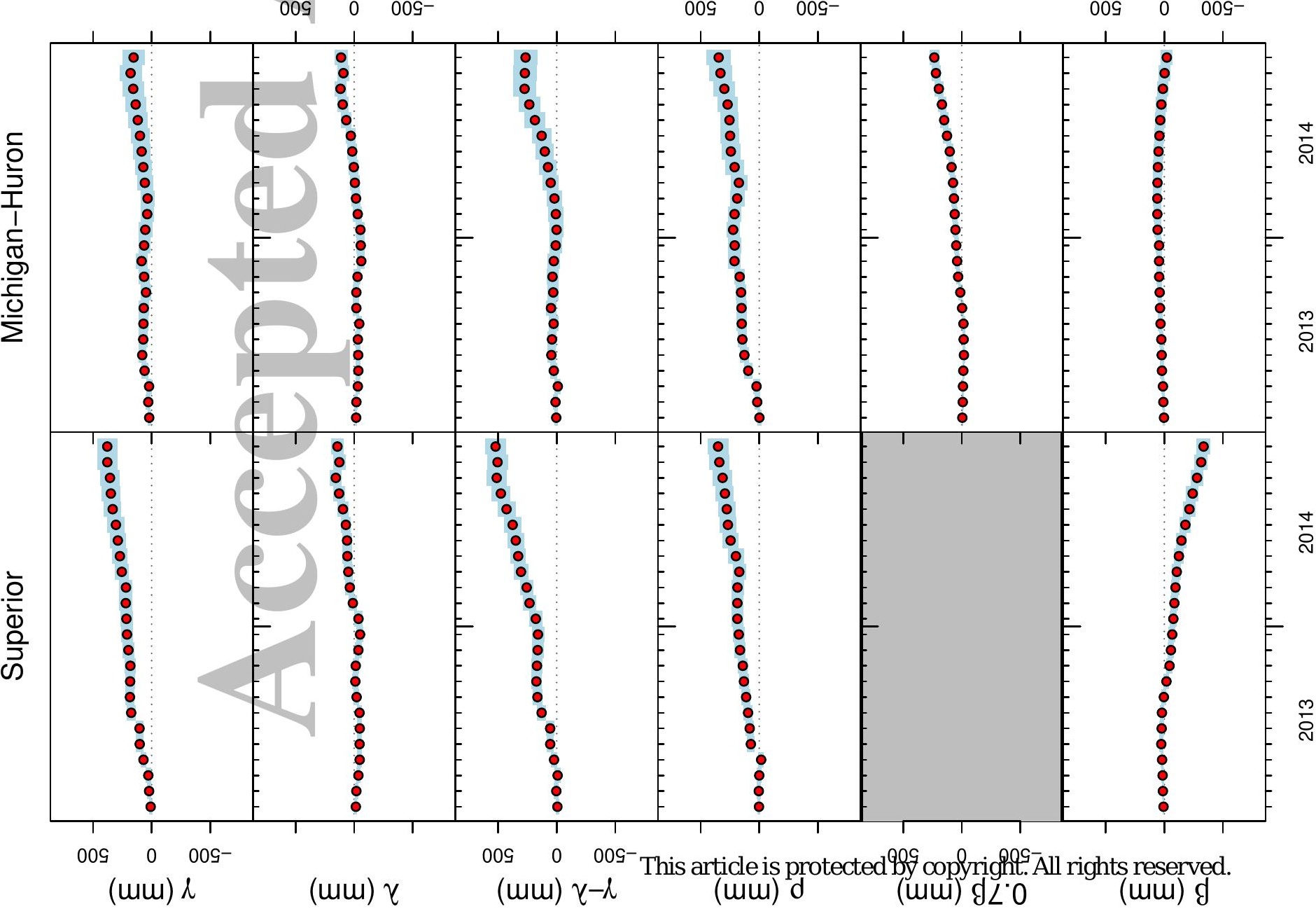

